ULTRAVIOLET RAMAN SPECTRAL SIGNATURE ACQUISITION: UV RAMAN SPECTRAL FINGERPRINTS

A. J. SEDLACEK III AND C. FINFROCK

SEPTEMBER 2001

ENVIRONMENTAL SCIENCES DEPARTMENT BROOKHAVEN NATIONAL LABORATORY UPTON, LONG ISLAND, NEW YORK 11973 


\section{DISCLAIMER}

This report was prepared as an account of work sponsored by an agency of the United States Government. Neither the United States Government nor any agency thereof, nor any employees, nor any of their contractors, subcontractors or their employees, makes any warranty, express or implied, or assumes any legal liability or responsibility for the accuracy, completeness, or any third party's use or the results of such use of any information, apparatus, product, or process disclosed, or represents that its use would not infringe privately owned rights. Reference herein to any specific commercial product, process, or service by trade name, trademark, manufacturer, or otherwise, does not necessarily constitute or imply its endorsement, recommendation, or favoring by the United States Government or any agency thereof or its contractors or subcontractors. The views and opinions of authors expressed herein do not necessarily state or reflect those of the United States Government or any agency thereof.

Available electronically at http://www.doe.gov/bridge

Available to U.S. Department of Energy and its contractors in paper fromU.S. Department of Energy Office of Scientific and Technical Information P.O. Box 62 Oak Ridge, TN 37831

(423) 576-8401

Available to the public from-

U.S. Department of Commerce National Technical Information Service 5285 Port Royal Road Springfield, VA 22131

(703) $487-4650$

\section{$\because$}

PRINTED ON RECYCLED PAPER 
BNL- 69453

Informal Report

\title{
ULTRAVIOLET RAMAN SPECTRAL SIGNATURE ACQUISITION: UV RAMAN SPECTRAL FINGERPRINTS
}

\author{
A. J. Sedlacek III and C. Finfrock \\ Environmental Sciences Department \\ Brookhaven National Laboratory \\ Upton, NY 11973-5000
}

September 2001

\author{
Year End Report \\ submitted to \\ Edgewood Chemical Biological Center (ECBC) \\ in support of the Raman spectroscopy research effort
}




\section{Executive Summary:}

As a member of the science-support part of the ITT-lead LISA development program, BNL is tasked with the acquisition of UV Raman spectral fingerprints and associated scattering cross-sections for those chemicals-of-interest to the program's sponsor. In support of this role, the present report contains the first installment of UV Raman spectral fingerprint data on the initial subset of chemicals. Because of the unique nature associated with the acquisition of spectral fingerprints for use in spectral pattern matching algorithms (i.e., CLS, PLS, ANN) great care has been undertaken to maximize the signal-to-noise and to minimize unnecessary spectral subtractions, in an effort to provide the highest quality spectral fingerprints.

This report is divided into 4 sections. The first is an Experimental section that outlines how the Raman spectra are performed. This is then followed by a section on Sample Handling. Following this, the spectral fingerprints are presented in the Results section where the data reduction process is outlined. Finally, a Photographs section is included.

\section{Experimental Section:}

Figure 1 is a schematic diagram of the experimental apparatus used to measure Raman cross sections. A Spectra- Physics MOPO-730 system generates continuously tunable radiation from $410 \mathrm{~nm}$ to $2000 \mathrm{~nm}$. The MOPO-730 is a BBO-based optical parametric oscillator (OPO) pumped by the third harmonic (355 $\mathrm{nm})$ of a $30 \mathrm{~Hz} \mathrm{Nd}$ :YAG laser. The UV light $(210-400 \mathrm{~nm})$ is obtained by doubling either the signal or the idler beam from the MOPO. The pulse width of the UV light is 3-4 ns, and the linewidth is approximately $0.3 \mathrm{~cm}^{-1}$. Photographs of the Raman system can be found at the end of this report.

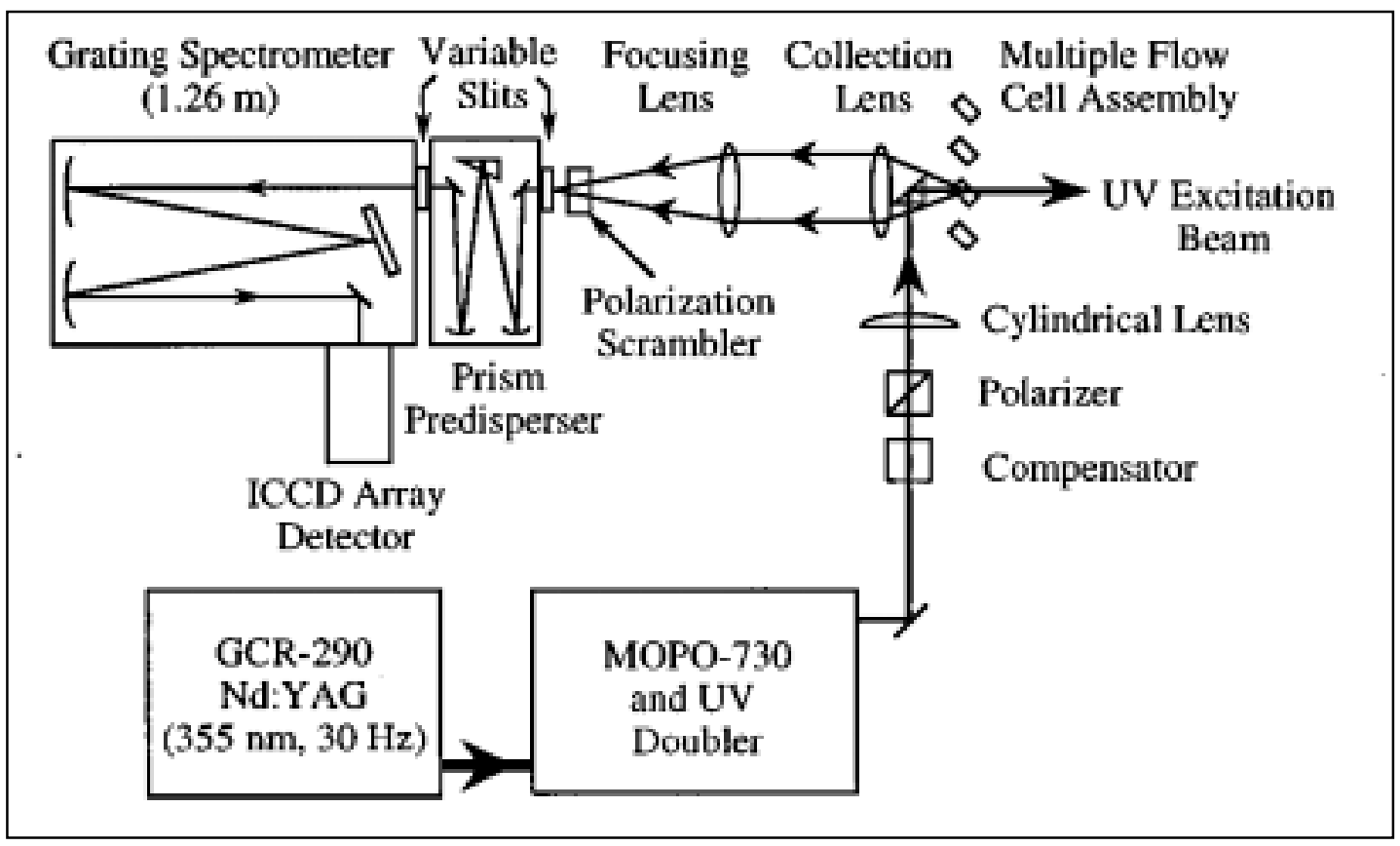

Figure 1: Schematic of Experimental Setup Used to Collect UV Raman Signatures

A $254 \mathrm{~mm}$ focal length cylindrical lens focuses the excitation light into the sample. The UV energy is 0.5 $\mathrm{mJ} /$ pulse or less, and the spot size at the sample is approximately $0.733 \mathrm{~mm}$. The scattered light is collected at $180^{\circ}$ with respect to the incident UV beam by a $50.8 \mathrm{~mm}$ diameter spherical lens $(f$ number $=1)$. The angle between the UV beam and the surface of the sample stream is $45^{\circ}$ to reduce back reflections from the cell walls. Another $50.8 \mathrm{~mm}$ diameter spherical lens focuses the scattered light into the prism predisperser. The $f$ number of the second lens matches the $f$ number of the prism predisperser and spectrometer for 
maximum throughput of the scattered light. The predisperser works as a sharp-cut bandpass filter with high throughput (40\%-50\%) and negligible aberration.

The spectrometer is a $1.26 \mathrm{~m}$ single stage monochromator (Spex Model 1269) with an 1800 grooves/mm grating. The width of the entrance slit in the spectrometer is controlled to reject elastically scattered laser light, while the resolution of Raman spectra is governed by the slit width of the predisperser. With this combination, we are able to measure Raman shifts of less than $200 \mathrm{~cm}^{-1}$ in deep UV with negligible

Rayleigh background. A crystalline quartz wedge polarization scrambler in front of the entrance slit of the predisperser depolarizes the polarized Raman signal before it enters the spectrometer.

The optical throughput of both the predisperser and the spectrometer has been measured at various wavelengths in the UV using a NIST standard $\mathrm{D}_{2}$ lamp. The spectra of a standard Hg lamp and known chemicals serve as wavelength calibrations for the predisperser and the monochromator.

The Raman spectra are captured by a gated, intensified CCD detector (Oriel Instaspec V, 1024X256 pixel array, $25 \mathrm{~mm}$ (and $18 \mathrm{~mm}$ ) window width) mounted at the exit port of the spectrometer. The CCD chip is cooled to $-25^{\circ} \mathrm{C}\left(-35^{\circ} \mathrm{C}\right)$ to yield a dark count of less than $2 \times 10^{-5}$ counts element ${ }^{-1} \mathrm{~s}^{-1}$. The adjustable gain of the intensifier is set to $\sim 50$ counts/photoelectron ( 150 counts/photoelectron) for all measurements. The Raman spectra are normalized to the measured response uniformity of the ICCD array.

\section{Sample Handling}

Preparation and handling of samples for analysis by UV Raman spectroscopy was conducted using the procedures, protocols and methods described below. Chemicals used in the analysis were obtained from reputable commercial research chemical suppliers. They were obtained in the highest purity commonly available to the research community. Certificates of analysis were obtained from the vendor for virtually all of the chemicals used in this project. Chemical purity was verified in-house by gas chromatography (HP 5890 Series 2 chromatograph outfitted with a $25 \mathrm{~m}$ x $0.32 \mathrm{~mm}$ x $0.52 \mu \mathrm{m}$ FFAP capillary column) for all tested liquids except SF-96 and HPLC grade water. In order to preserve the purity of the chemicals tested, only certain container and sample handling materials were permitted. Acceptable sample handling materials were glass, Teflon, PFA (perfluoro (alkoxyalkane) copolymer), PEEK (polyaryl ether ether ketone) and stainless steel, all of which were subjected to the following cleaning protocol. All materials were ultrasonically cleaned in warm distilled water and ultrasonic cleaner detergent solution for a minimum of fifteen minutes. The materials were then rinsed with copious amounts of distilled water and then rinsed with spectroscopic grade methanol, followed by drying in an $80^{\circ} \mathrm{C}$ glassware-drying oven. The only departure from this protocol was the method for cleaning the magnetic drive pumps used with the windowless flow cell. As these pumps have interior spaces that are not easily accessible for cleaning, sufficient pumps were obtained to allow compatible chemicals to have dedicated pumps. In the event that a pump did require cleaning, the following method was applied. The pump was allowed to pump itself dry into a waste vessel. Several aliquots of appropriate solvents were cycled through the pumps alternated with drying of the interior with dry filtered compressed air. This was done over the course of several hours. The final rinse of a pump was with a solvent of high vapor pressure, such as cyclohexane, which was then easily removed by flowing dry filtered compressed air through the pump for several hours while it was slowly rotating.

Some samples required dilution prior to analysis. Dilutions, when required, were prepared gravimetrically using a Mettler AE 100 or a Mettler SB 8001 electronic balance, as dictated by the amount of sample being prepared. Concentrations are expressed in terms of weight percent, in other words, mass of minor component divided by total mass, times 100 . 
In order to address potential reabsorption, UV/VIS absorption spectra of all samples were collected with a Perkin-Elmer 320 spectrophotometer. In addition to this, NIR Raman spectra were collected using a Bruker IFS-66 FT spectrometer outfitted with a NIR Raman attachment (FRA-106).

Two sample-handling systems were developed to facilitate liquid sample exposure to the UV Raman spectroscopy system. A closed system using quartz flow cells and a syringe pump was developed, as well as a "windowless" system consisting of an open flow cell and small magnetic drive chemical pumps. The closed system consisted of a Harvard Apparatus " 33 " syringe pump, an array of ten milliliter glass syringes, a set of four way control valves, a collection of quartz flow cells of varying path length, a set of glass sample reservoirs, required connecting tubing, and a positioning system to locate the cells in the beam path. The syringe pump was programmed to alternately draw and push the sample between the reservoir and syringe body via the connecting tubing and the quartz cell. This system provided a completely closed environment for the sample with good control of the flow rate and path length. Evaporation of samples with high vapor pressure was well suppressed in this system. A disadvantage of this system was the spectroscopic contribution of the quartz cells containing the samples. The "windowless" sample introduction system circumvented this problem. The "windowless" system consisted of an array of magnetic drive chemical pumps from Micropump ${ }^{\circledR}$ Corp., an array of glass sample reservoirs, appropriate connecting tubing, and a specially fabricated Teflon and glass cell. The upper member of the cell is machined from Teflon and is a hollow cylinder with a narrow slot milled along the diameter of the end. At each end of the slot, small glass rods are inserted into drilled holes that terminate the ends of the slot. This is mounted in a fixture so that the slot and glass rods point vertically downward. Immediately below the glass rods is a Teflon well that has a PFA compression fitting below for attachment of a glass sample reservoir. The pump is connected to draw sample from the bottom of the reservoir and deliver it to the interior of the upper Teflon member. The sample flows out of the slot and wets the glass rods, forming a falling film or sheet of sample, which is collected back into the reservoir by the well. This assembly may be mounted to the same positioning system as the quartz cells described above, and is typically positioned so that the beam passes through the falling film formed between the glass rods. This system has the advantage of eliminating any contribution to the spectrum by cell materials in the beam path, but the flow rate and sample film characteristics are somewhat dictated by the sample's surface tension and wetting characteristics.

Solid samples were fixed to the positioning system used for the cells above by appropriate clamps, and positioned in the beam manually.

\section{Results:}

As an illustrative example of the data reduction process, we will use cyclohexane. Shown in Figure 2 are the 4 raw spectral regions collected using the system described above. These Spectra are then corrected for ICCD pixel-to-pixel variation, the instrumentation response function and ICCD dark current. Following these corrections the individual spectra are spliced together to form the desired spectral fingerprint. Once completed, the spectral features' (in the present case the cyclohexane modes) pixel locations are recorded as a function of Raman shift. Figure 3 shows the calibration for our example. After application of this calibration curve, the resulting spectrum is then corrected for instrumentation throughput and, if necessary, signal reabsorption as a function of Raman shift. Shown in Figure 4 is the final UV Raman spectrum for cyclohexane. Also shown in Figure 4 is the Raman spectrum collected using the Bruker FTS-66 NIR Raman spectrometer. As can be clearly seen, the UV spectrum correlates very well with the spectrum collected in the NIR. It should also be pointed out that use of the windowless flow cell enables acquisition of Raman spectral features well below $500 \mathrm{~cm}^{-1}$, as evidenced by the clear observation of the 382.7 and $425.2 \mathrm{~cm}^{-1}$ modes of cyclohexane. 

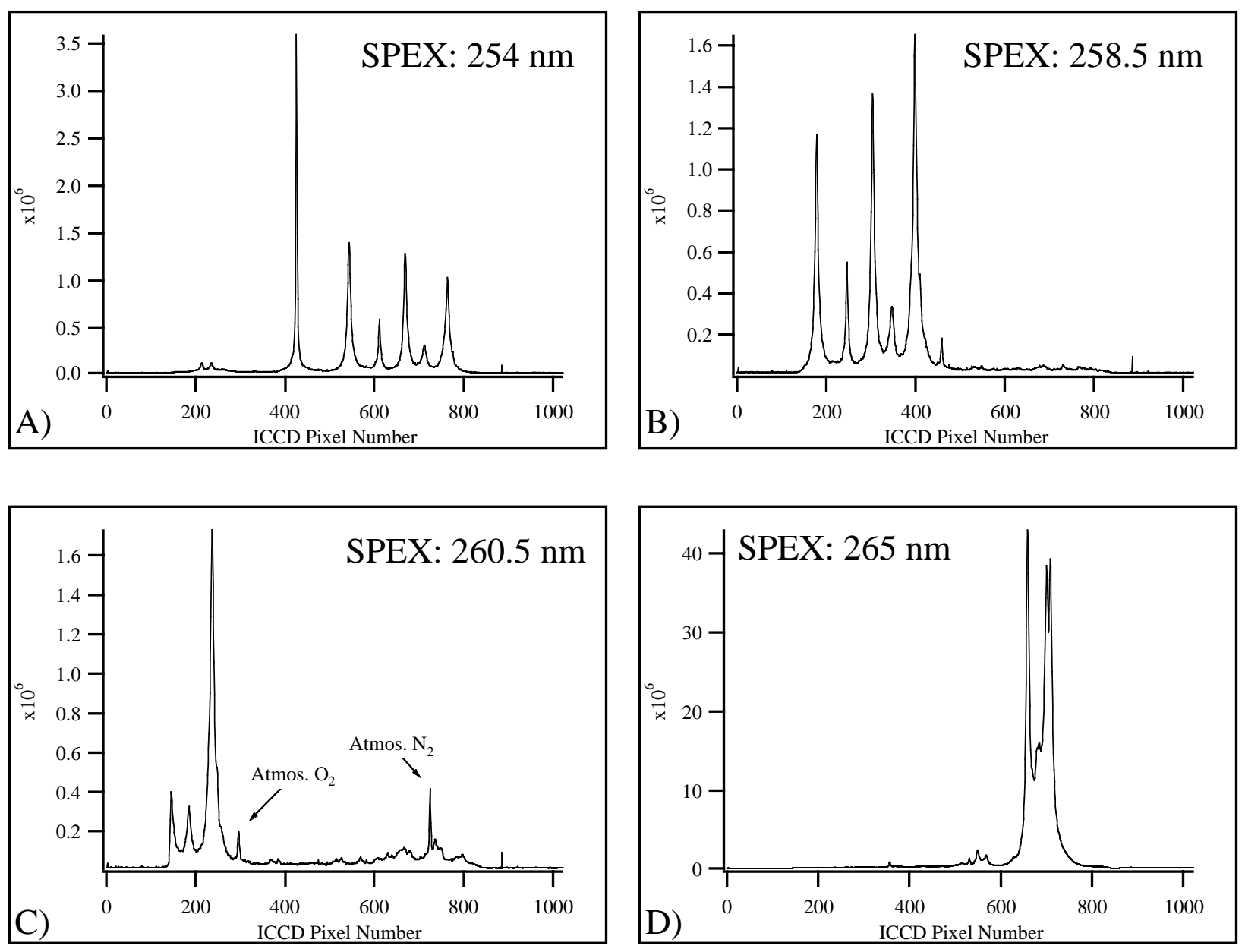

Figure 2: Uncorrected Individual Spectral Slices for Cyclohexane.

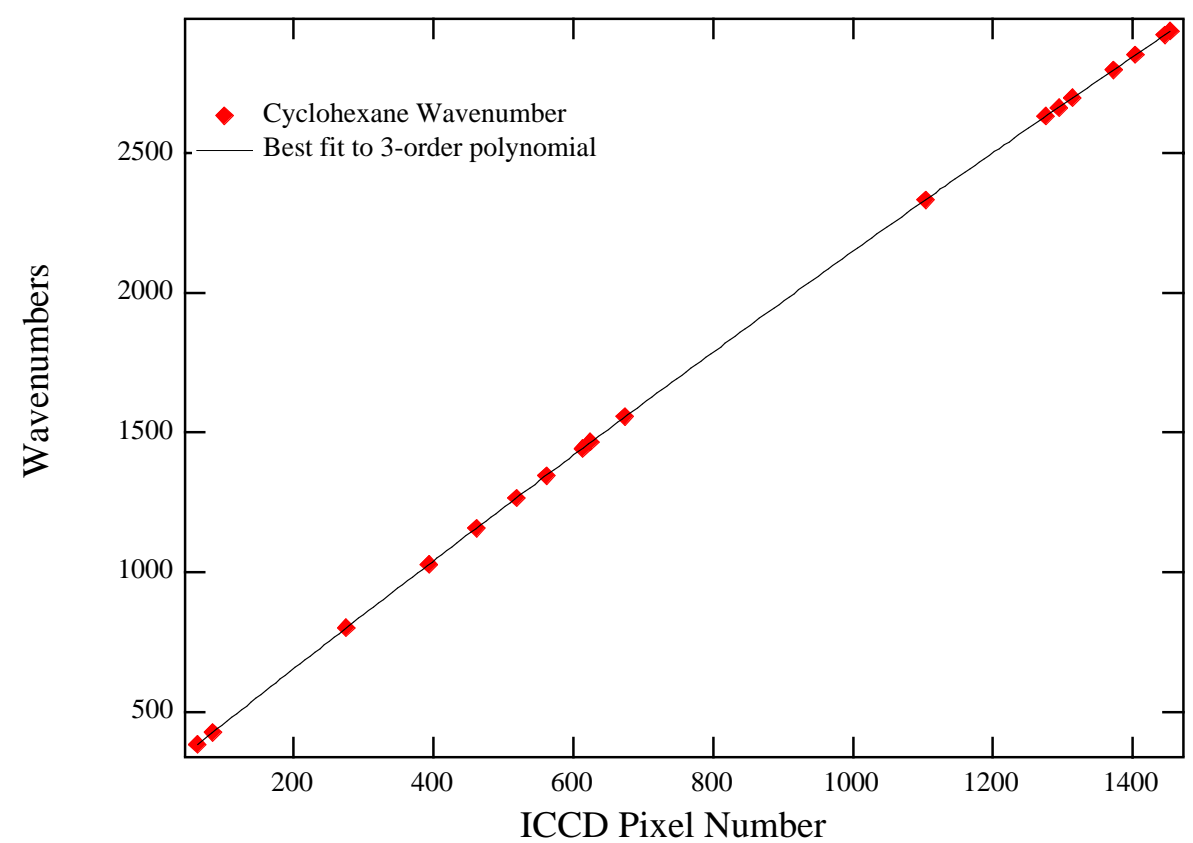

Figure 3: Wavenumber to ICCD Pixel Number Calibration

$$
-4 \text { - }
$$




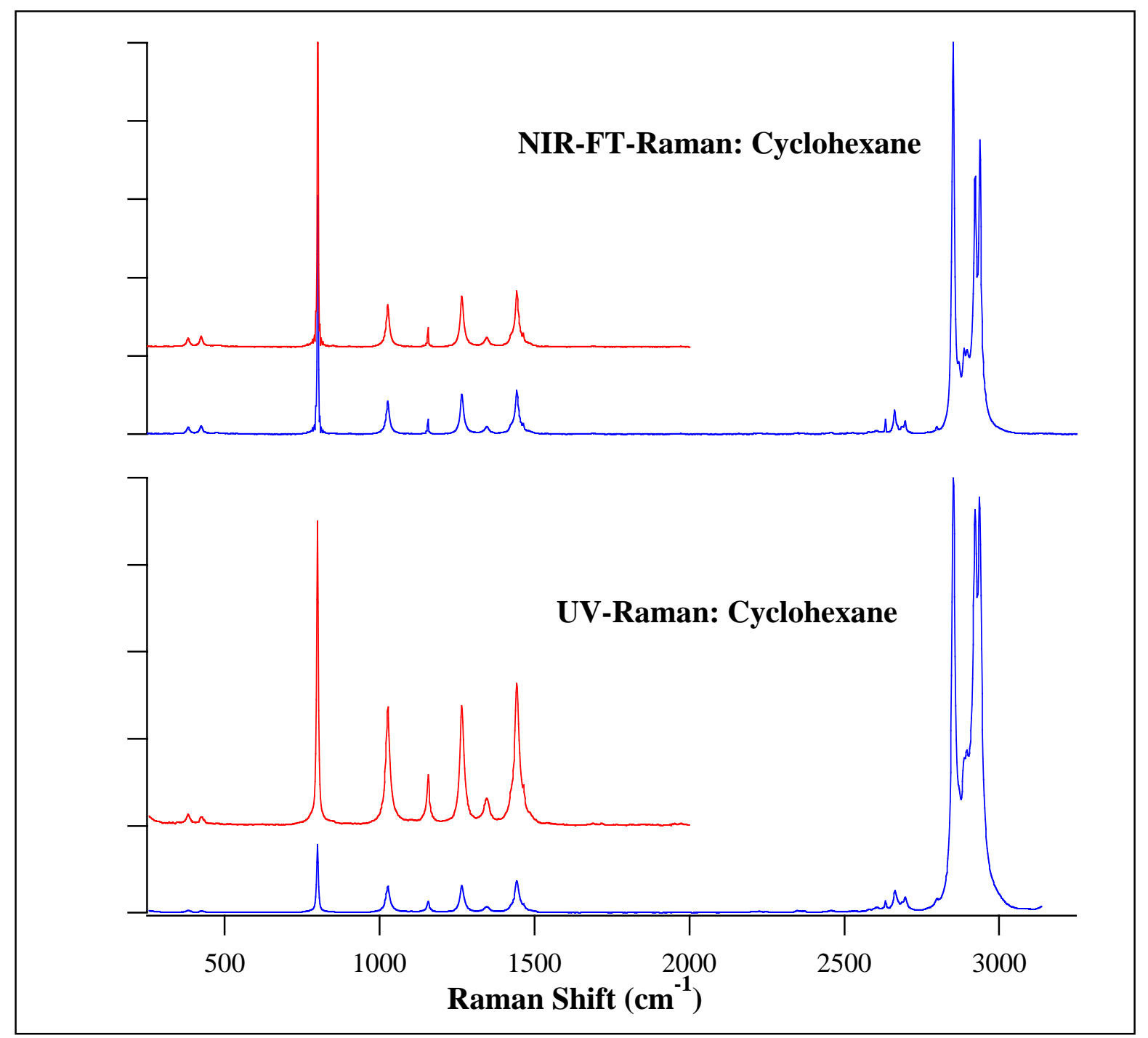

Figure 4: UV Raman spectrum of neat cyclohexane. Upper trace is the NIR Raman spectrum of cyclohexane for comparison purposes.

\section{Summary of Chemical Properties and Absorbance Cross-Sections}

\begin{tabular}{|l|l|l|l|}
\hline \multicolumn{1}{|c|}{ Chemical Species } & \multicolumn{1}{|c|}{ M.W. } & \multicolumn{1}{|c|}{ Density (g/cc) } & $\begin{array}{l}\text { UV Absorbance Cross-section } \\
\text { at 248 nm (cm } / \text { molecule })^{\dagger}\end{array}$ \\
\hline acetonitrile & 41.05 & 0.786 & $\mathrm{NA}^{\S}$ \\
\hline cyclohexane & 84.16 & 0.779 & $\mathrm{NA}$ \\
\hline DeM & 160.17 & 1.055 & $1.25 \pm 0.04 \times 10^{-20}$ \\
\hline MeS & 152.1 & 1.174 & $7.75 \pm 0.11 \times 10^{-18}$ \\
\hline n-hexane & 86.18 & 0.6603 & NA \\
\hline PIBM & 300,000 & n/a & $4.89 \pm 0.17 \times 10^{-16}$ \\
\hline SF96 & 13,700 & 0.973 & $1.24 \pm 0.01 \times 10^{-20}$ \\
\hline water & 18.01 & 1 & NA \\
\hline
\end{tabular}

${ }^{\S}$ NA:no absorbance

${ }^{\dagger}$ Quoted cross-section error bars are 2- $\sigma$ 
The spectra below are in alphabetical order. Quoted spectral locations were generated by curve fitting (a series of Voigt lineshapes) to a given Raman spectrum. Data reduction was accomplished using Igor Pro.

\section{Acetonitrile}

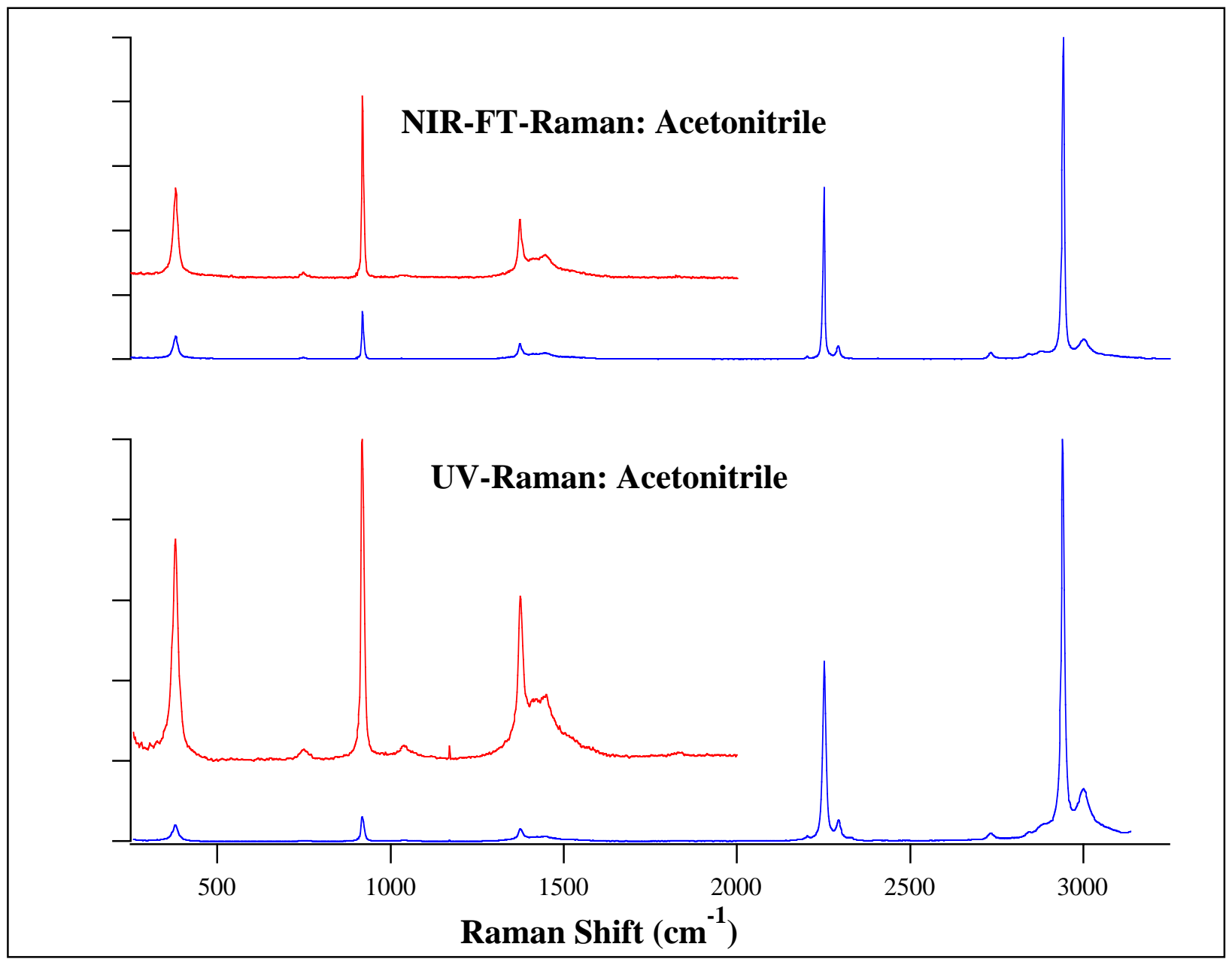

\begin{tabular}{|l|}
\hline Raman Positions $\left(\mathrm{cm}^{-1}\right)$ \\
\hline 377.407 \\
\hline 917.766 \\
\hline 1373.94 \\
\hline 1437.72 \\
\hline 2251.55 \\
\hline 2292.25 \\
\hline 2731.98 \\
\hline 2939.96 \\
\hline 3000.16 \\
\hline
\end{tabular}




\section{Concrete}

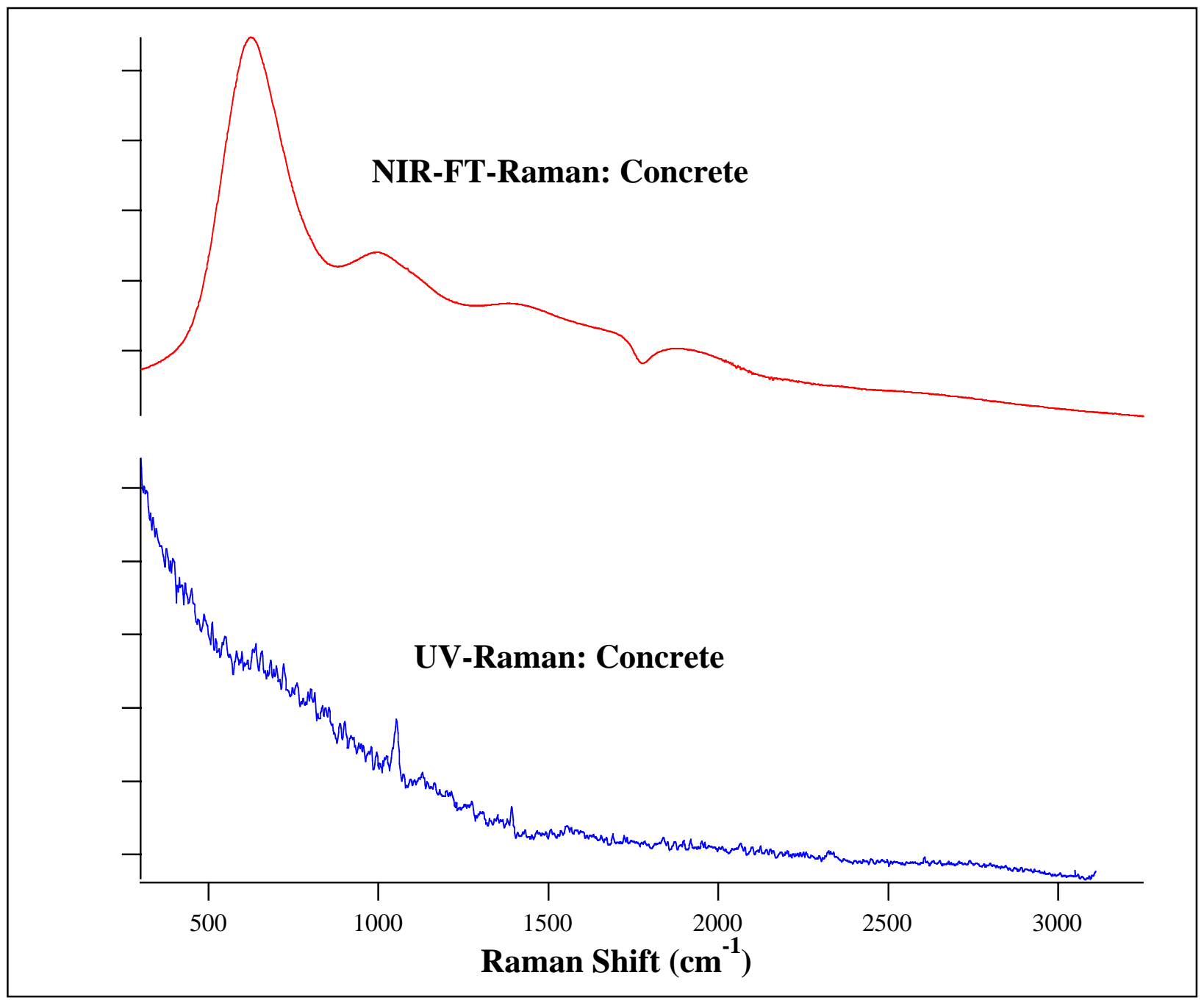

\begin{tabular}{|l|}
\hline Raman Shift $\left(\mathrm{cm}^{-1}\right)$ \\
\hline 1052.82 \\
\hline 1391.64 \\
\hline
\end{tabular}

Featureless. 


\section{Cyclohexane}

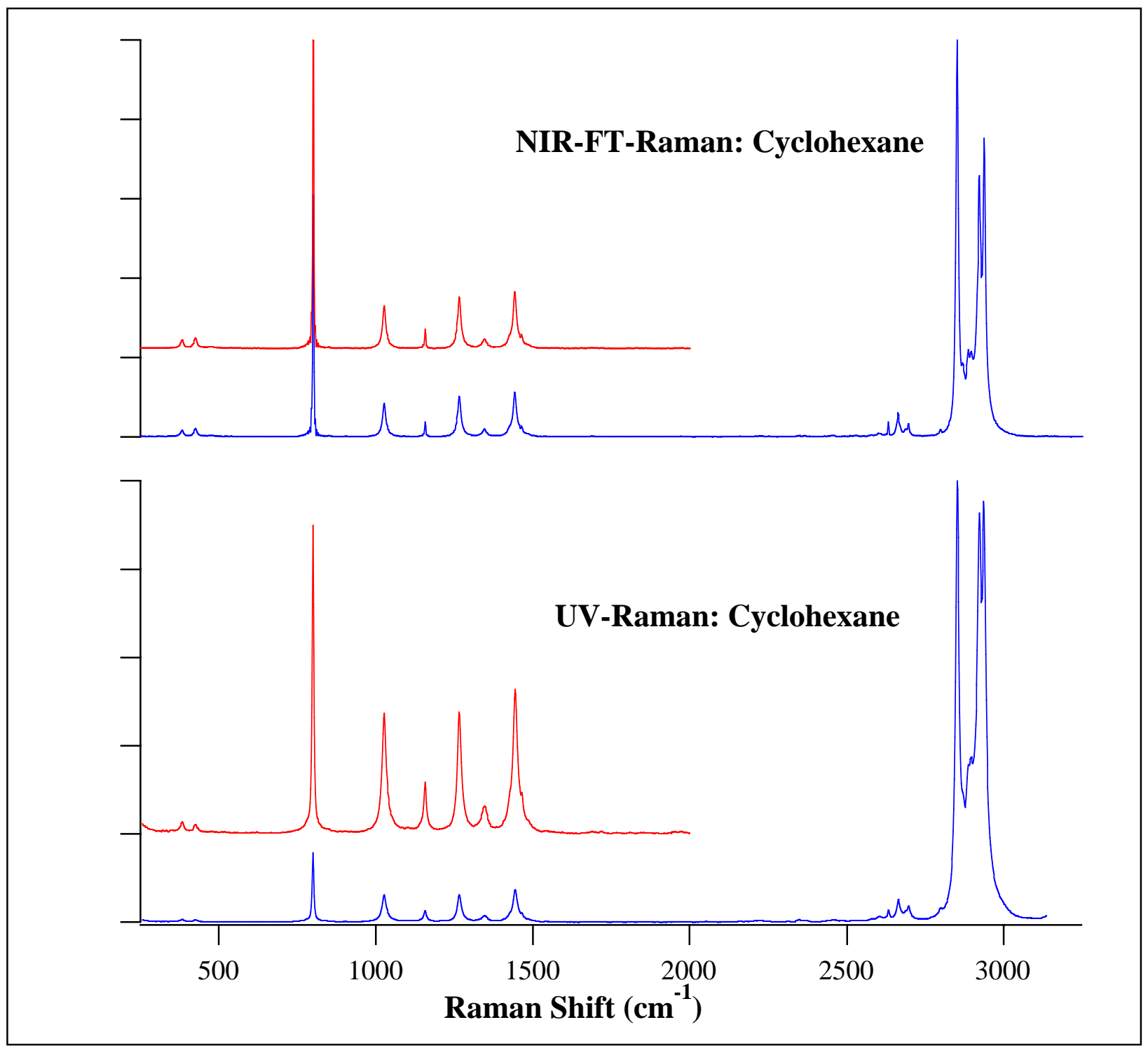

\begin{tabular}{|l|l|}
\hline \multicolumn{2}{|c|}{ Raman Shift $\left(\mathrm{cm}^{-1}\right)$} \\
\hline 382.675 & 2695 \\
\hline 425.219 & 2797.68 \\
\hline 799.615 & 2850.44 \\
\hline 1026.5 & 2886.06 \\
\hline 1156.14 & 2921.58 \\
\hline 1265.31 & 2935.09 \\
\hline 1345.23 & \\
\hline 1465.62 & \\
\hline 1442.69 & \\
\hline 2631.3 & \\
\hline 2662.33 & \\
\hline
\end{tabular}

- 8 - 


\section{Diethyl Malonate (DEM)}

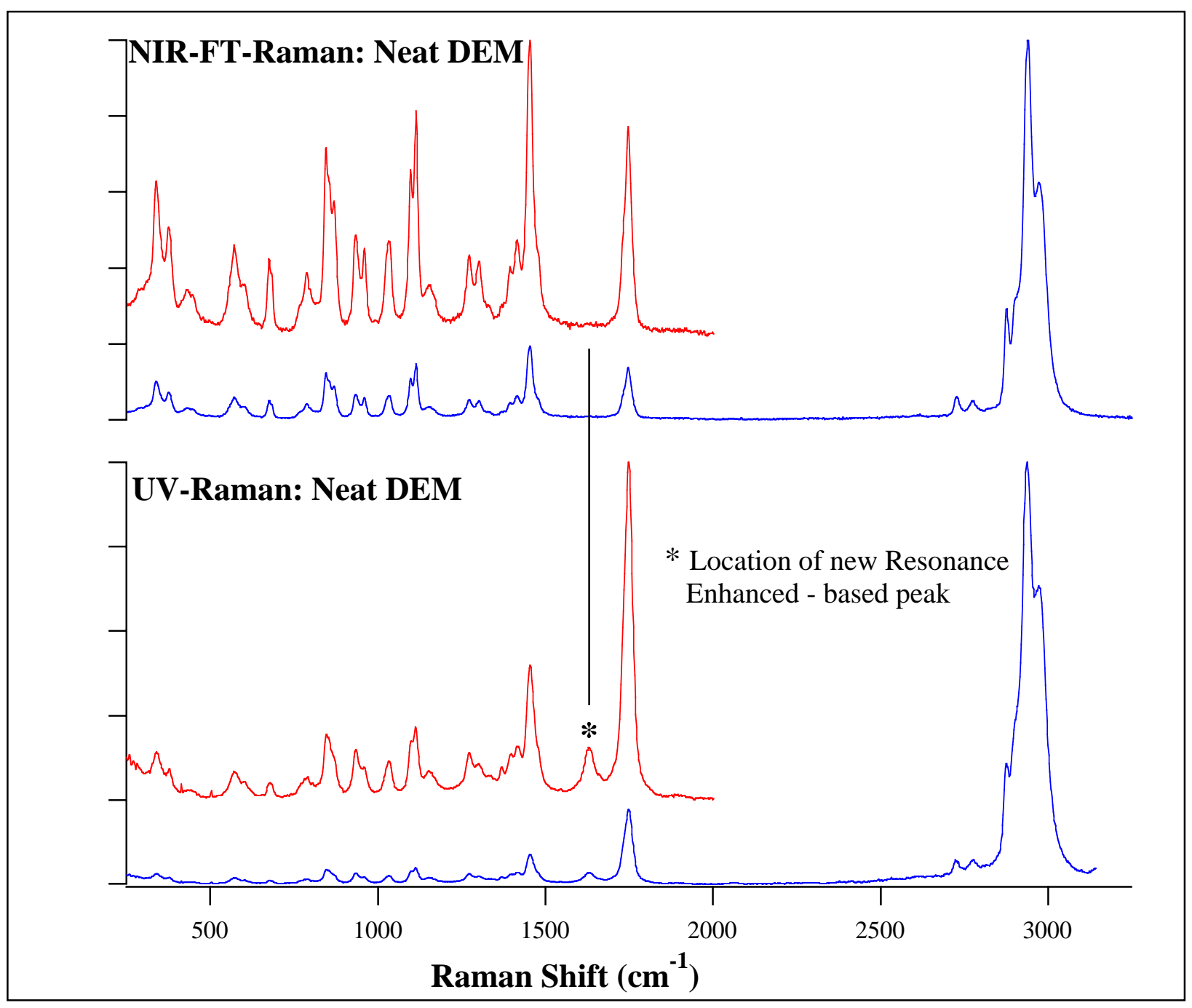

\begin{tabular}{|l|l|l|}
\hline \multicolumn{3}{|c|}{ Raman Shift $\left(\mathrm{cm}^{-1}\right)$} \\
\hline 340.368 & 946.646 & 1416.34 \\
\hline 376.239 & 1031.13 & 1454.71 \\
\hline 568.057 & 1098.84 & 1629.71 \\
\hline 595.222 & 1114.06 & 1746.35 \\
\hline 678.746 & 1151.89 & 2725.11 \\
\hline 785.627 & 1271.23 & 2773.66 \\
\hline 845.176 & 1293.22 & 2873.33 \\
\hline 863.538 & 1368.27 & 2898.98 \\
\hline 931.958 & 1395.83 & 2934.98 \\
\hline
\end{tabular}

The UV Raman spectrum of DeM is unique is that a new peak is readily observable $\left(1629.7 \mathrm{~cm}^{-1}\right)$ under $248 \mathrm{~nm}$ illumination. Such features can be observed in RR depending upon the interactions between the ground state and an upper electronic state. 
Methyl Salicylate (MeS) in Acetonitrile: $0.15 \%(w / w)$

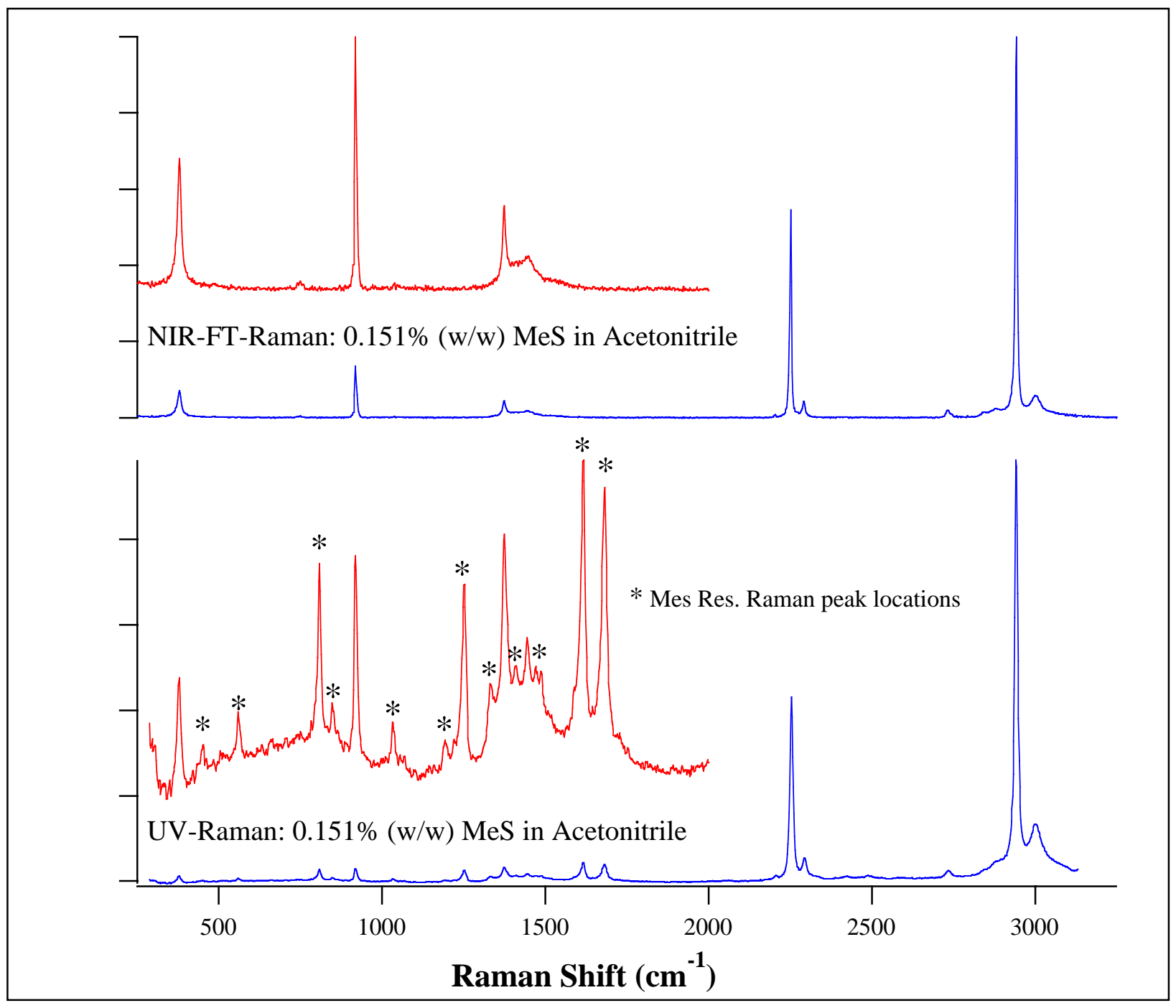

\begin{tabular}{|l|l|}
\hline \multicolumn{2}{|c|}{ Raman Shift $\left(\mathrm{cm}^{-1}\right)$} \\
\hline 377.675 & 1409.02 \\
\hline 451.145 & 1412.23 \\
\hline 560.164 & 1443.49 \\
\hline 806.998 & 1480.41 \\
\hline 849.67 & 1602.8 \\
\hline 918.706 & 1615.4 \\
\hline 1033.09 & 1679.74 \\
\hline 1193.59 & 2252.91 \\
\hline 1250.4 & 2293.8 \\
\hline 1333.92 & 2941.26 \\
\hline 1374.45 & 3002.06 \\
\hline
\end{tabular}

As evidence in the graph above, $\mathrm{MeS}$ is undergoing a very large resonance-enhancement at $248 \mathrm{~nm}$. 
Methyl Salicylate (MeS) in Water: 0.054\% (w/w). Comparison with $0.15 \% \mathrm{MeS}$ in Acetonitrile

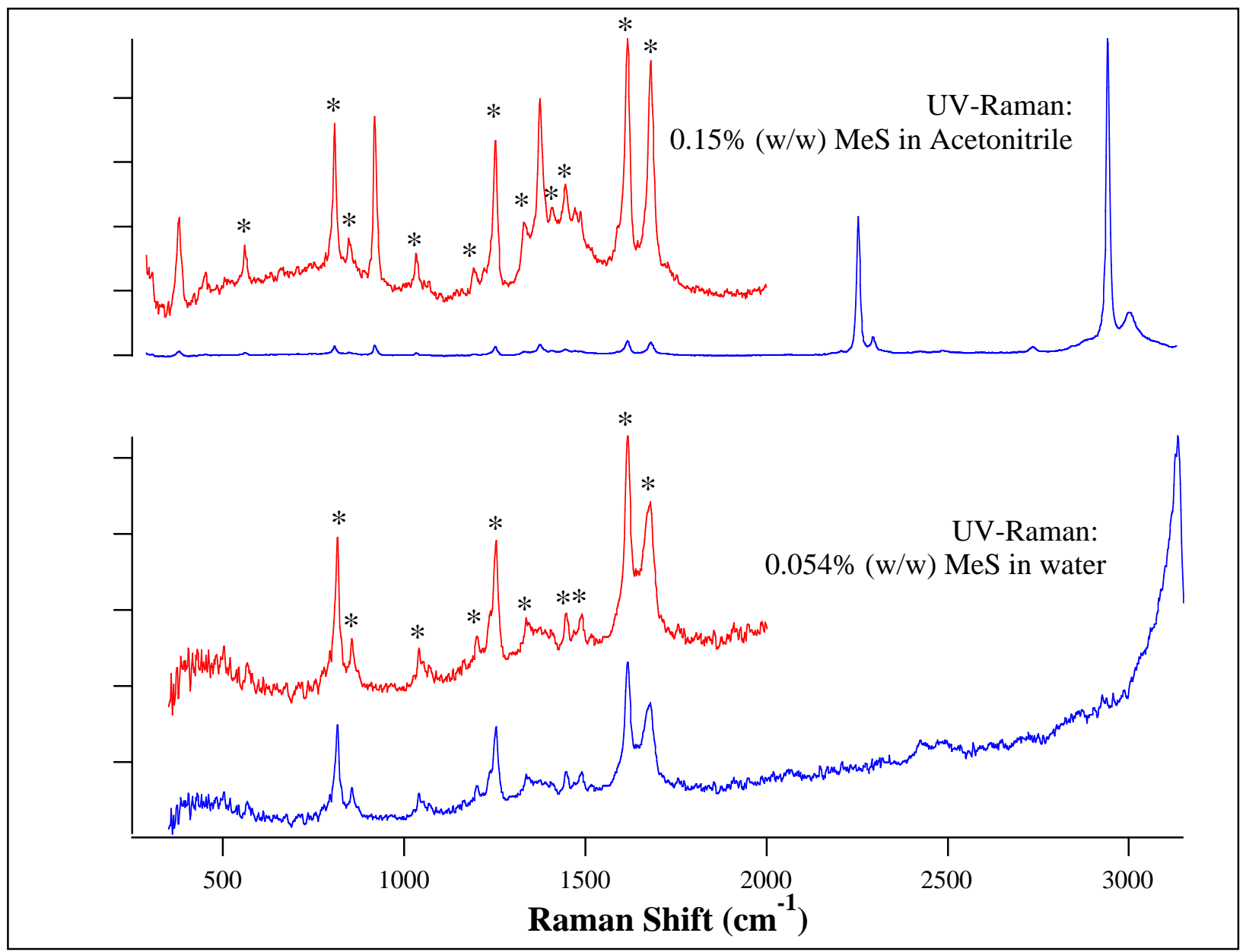

\begin{tabular}{|l|}
\hline \multicolumn{1}{|c|}{ Raman Shift $\left(\mathrm{cm}^{-1}\right)$} \\
\hline 814.772 \\
\hline 855.631 \\
\hline 1040.86 \\
\hline 1200.7 \\
\hline 1235.71 \\
\hline 1252.22 \\
\hline 1339.94 \\
\hline 1383.51 \\
\hline 1446.75 \\
\hline 1487.44 \\
\hline 1615.71 \\
\hline 1674.15 \\
\hline
\end{tabular}

Comparison to the MeS locations in the acetonitrile reveals that some shifts are taking place. See page 11 and page 13 for MeS in acetonitrile and neat MeS (as measured in with the FT-Raman spectrometer). 


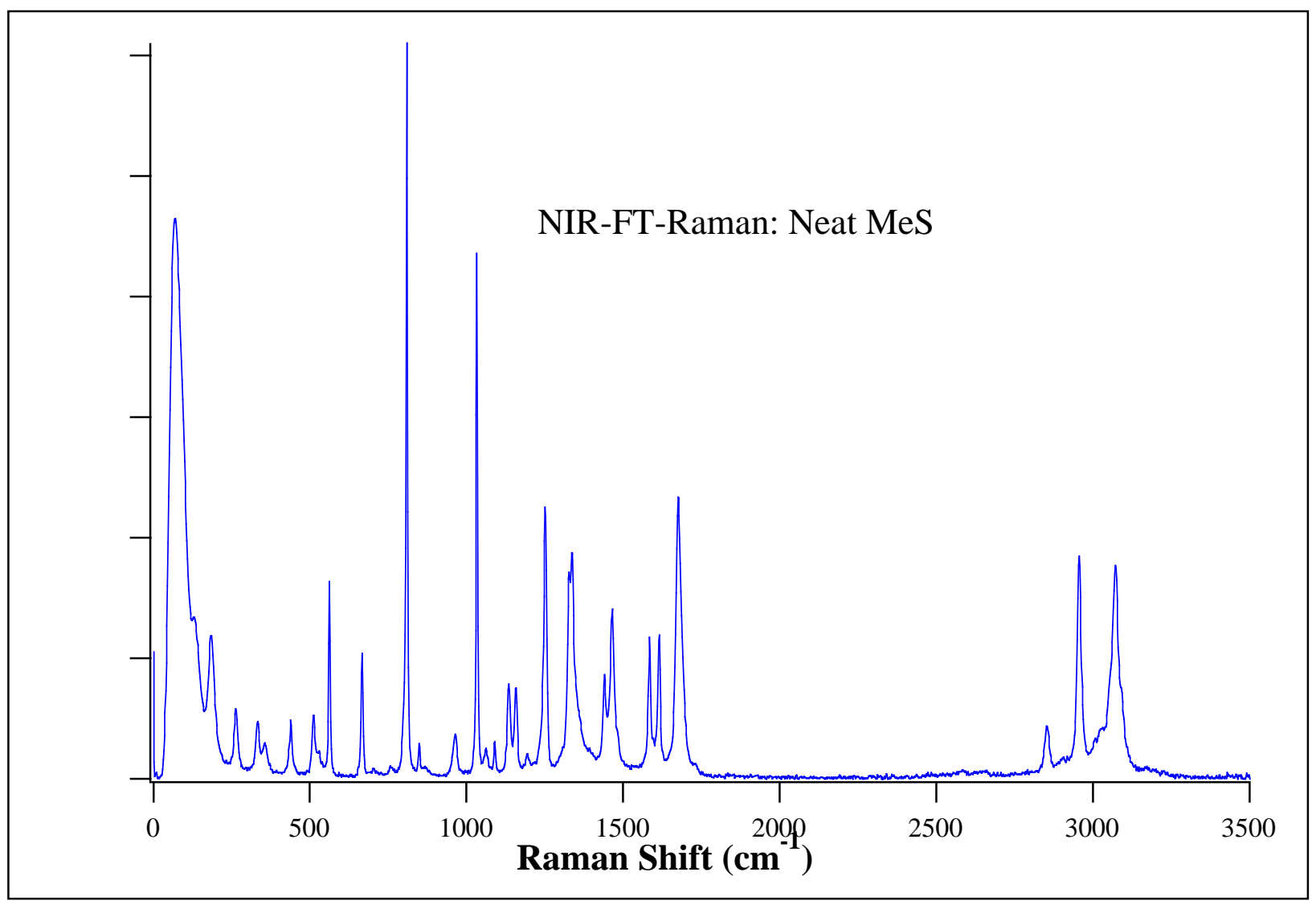

\begin{tabular}{|l|l|l|}
\hline \multicolumn{3}{|c|}{ Raman Shift $\left(\mathrm{cm}^{-1}\right)$} \\
\hline 185.89 & 1134.7 & 3092.31 \\
\hline 264.957 & 1155.91 & \\
\hline 334.381 & 1250.4 & \\
\hline 355.595 & 1327.54 & \\
\hline 438.519 & 1335.26 & \\
\hline 511.8 & 1441.32 & \\
\hline 561.941 & 1464.46 & \\
\hline 666.078 & 1583.97 & \\
\hline 758.644 & 1613.93 & \\
\hline 808.784 & 1677.05 & \\
\hline 847.354 & 2852.93 & \\
\hline 964.99 & 2955.34 & \\
\hline 1032.49 & 3024.06 & \\
\hline 1061.41 & 3054.11 & \\
\hline 1090.34 & 3071.39 & \\
\hline
\end{tabular}

The very large absorption cross-section for MeS precluded acquisition of a UV-Raman spectra from a neat sample. 


\section{n-Hexane}

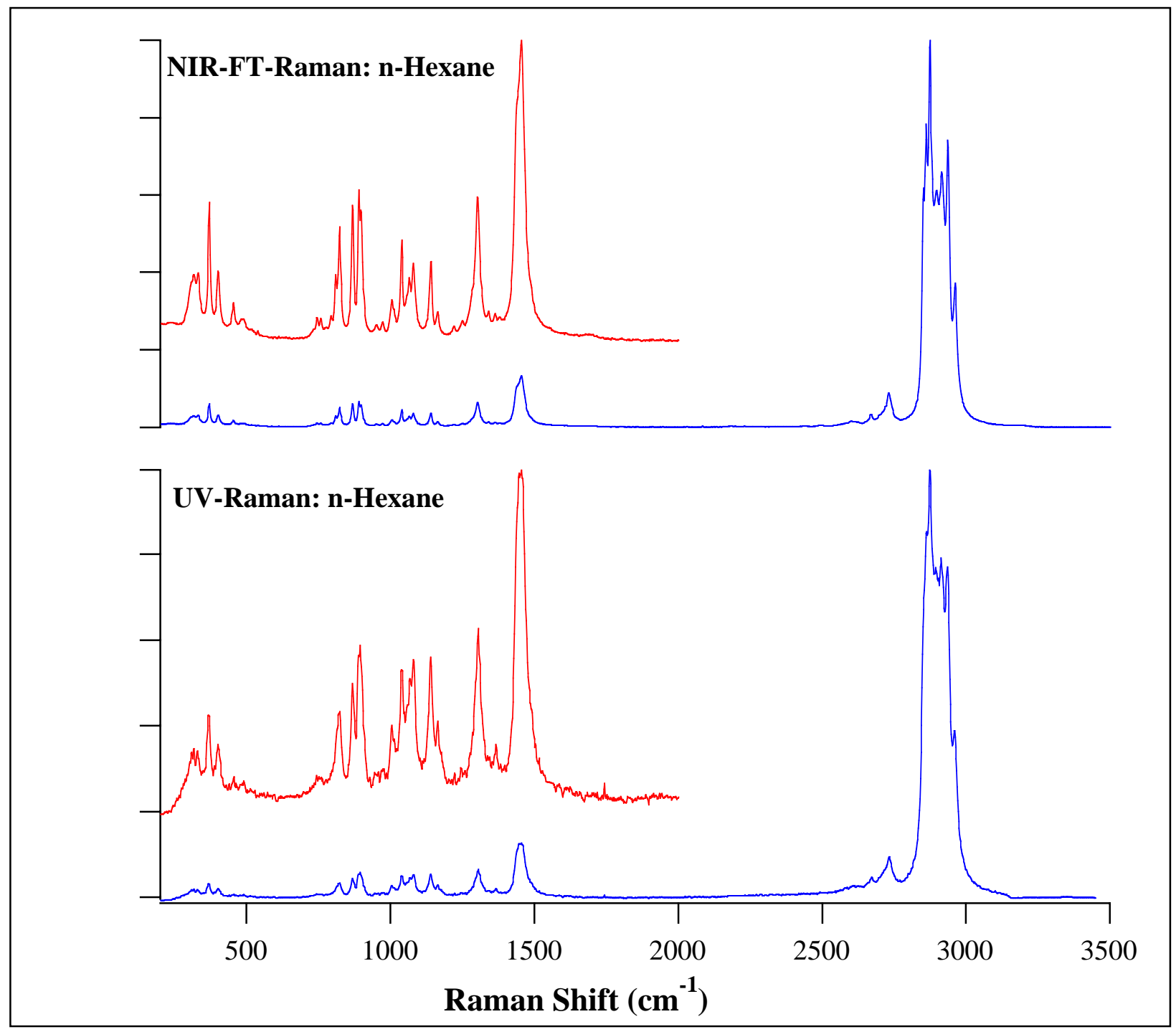

\begin{tabular}{|l|l|}
\hline \multicolumn{2}{|c|}{ Raman Shift $\left(\mathrm{cm}^{-1}\right)$} \\
\hline 311.93 & 1165.07 \\
\hline 329.545 & 1356.45 \\
\hline 367.367 & 1451.39 \\
\hline 400.116 & 2654.08 \\
\hline 454.314 & 2729.46 \\
\hline 818.937 & 2855.12 \\
\hline 866.99 & 2873.31 \\
\hline 892.993 & 2894.24 \\
\hline 1004.11 & 2914.42 \\
\hline 1038.08 & 2935.43 \\
\hline 1070.38 & 2960.94 \\
\hline 1080.02 & \\
\hline 1138.56 & \\
\hline
\end{tabular}




\section{Polyisobutyl Methacrylate: (PIBM);}

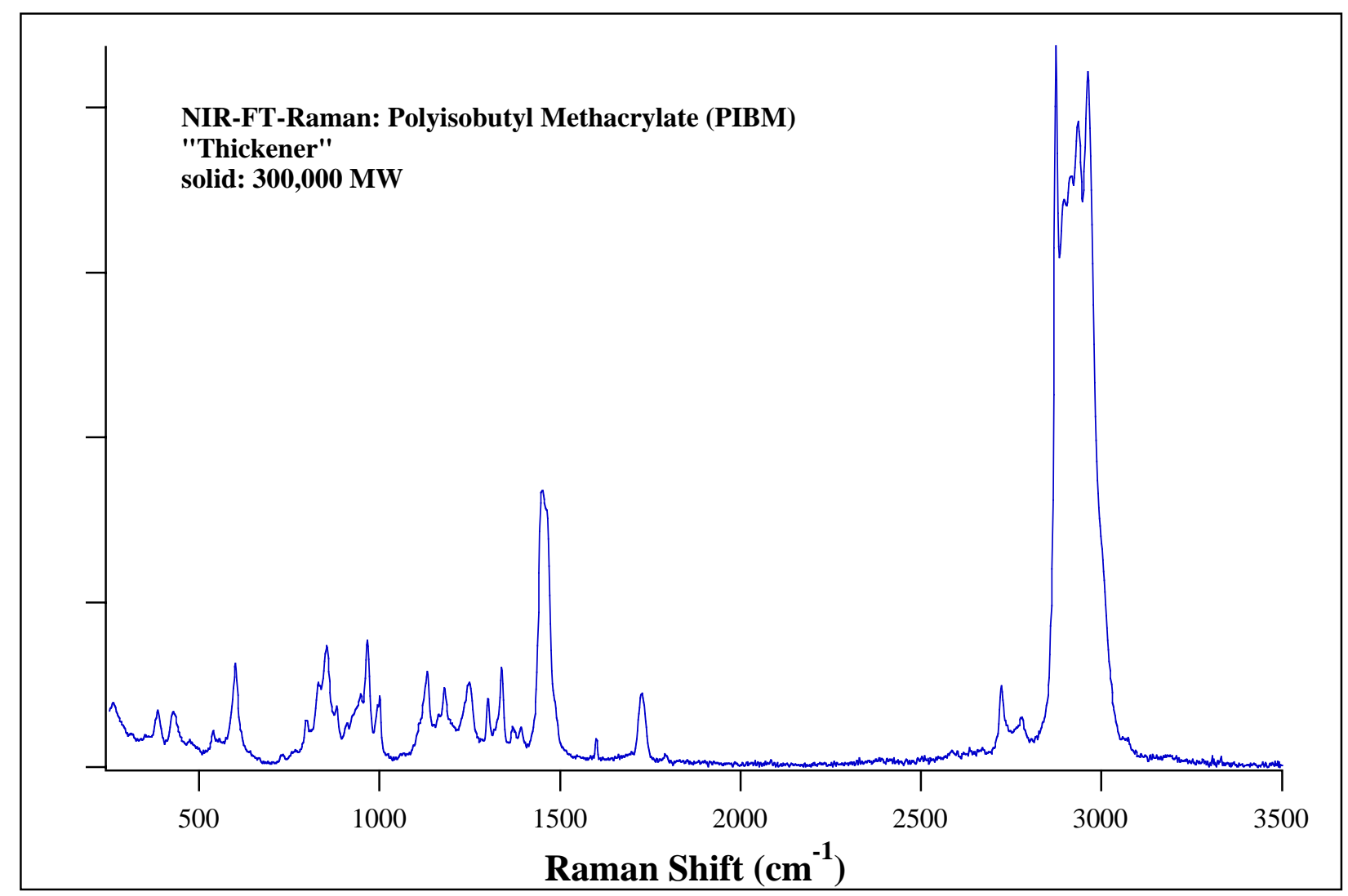

\begin{tabular}{|l|l|}
\hline \multicolumn{2}{|c|}{ Raman Shift $\left(\mathrm{cm}^{-1}\right)$} \\
\hline 261.187 & 1337.03 \\
\hline 384.043 & 1370.07 \\
\hline 430.571 & 1390.28 \\
\hline 544.625 & 1446.43 \\
\hline 599.678 & 1600.11 \\
\hline 796.694 & 1725.82 \\
\hline 829.501 & 1791.09 \\
\hline 852.916 & 2722.11 \\
\hline 879.63 & 2766.42 \\
\hline 1461.52 & 2871.93 \\
\hline 940.425 & 2888.52 \\
\hline 965.565 & 2916.89 \\
\hline 993.406 & 2935.9 \\
\hline 1000.64 & 2961.51 \\
\hline 1123.39 & 2997.64 \\
\hline 1130.81 & \\
\hline 1178.78 & \\
\hline 1238.66 & \\
\hline 1248.86 & \\
\hline 1299.87 & \\
\hline
\end{tabular}




\section{SF96 Silicone Oil}

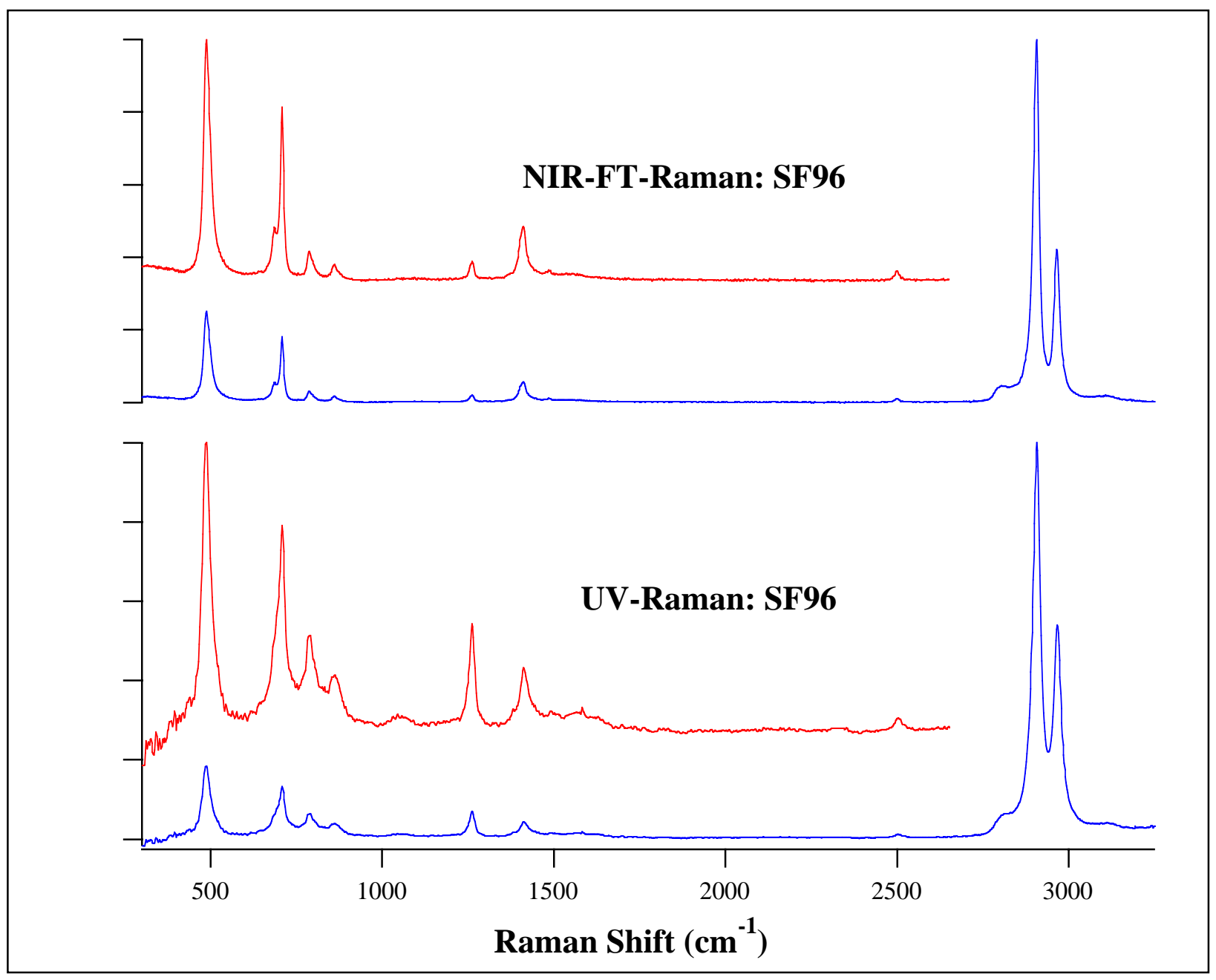

\begin{tabular}{|l|}
\hline \multicolumn{1}{|c|}{ Raman Shift $\left(\mathrm{cm}^{-1}\right)$} \\
\hline 487.506 \\
\hline 705.206 \\
\hline 789.66 \\
\hline 860.241 \\
\hline 1260.73 \\
\hline 1414.47 \\
\hline 2815.66 \\
\hline 2905.26 \\
\hline 2965.96 \\
\hline
\end{tabular}

This chemical species is highly desirable as a candidate chemical due to it simple Raman spectrum, minimal absorption and ease of use. 


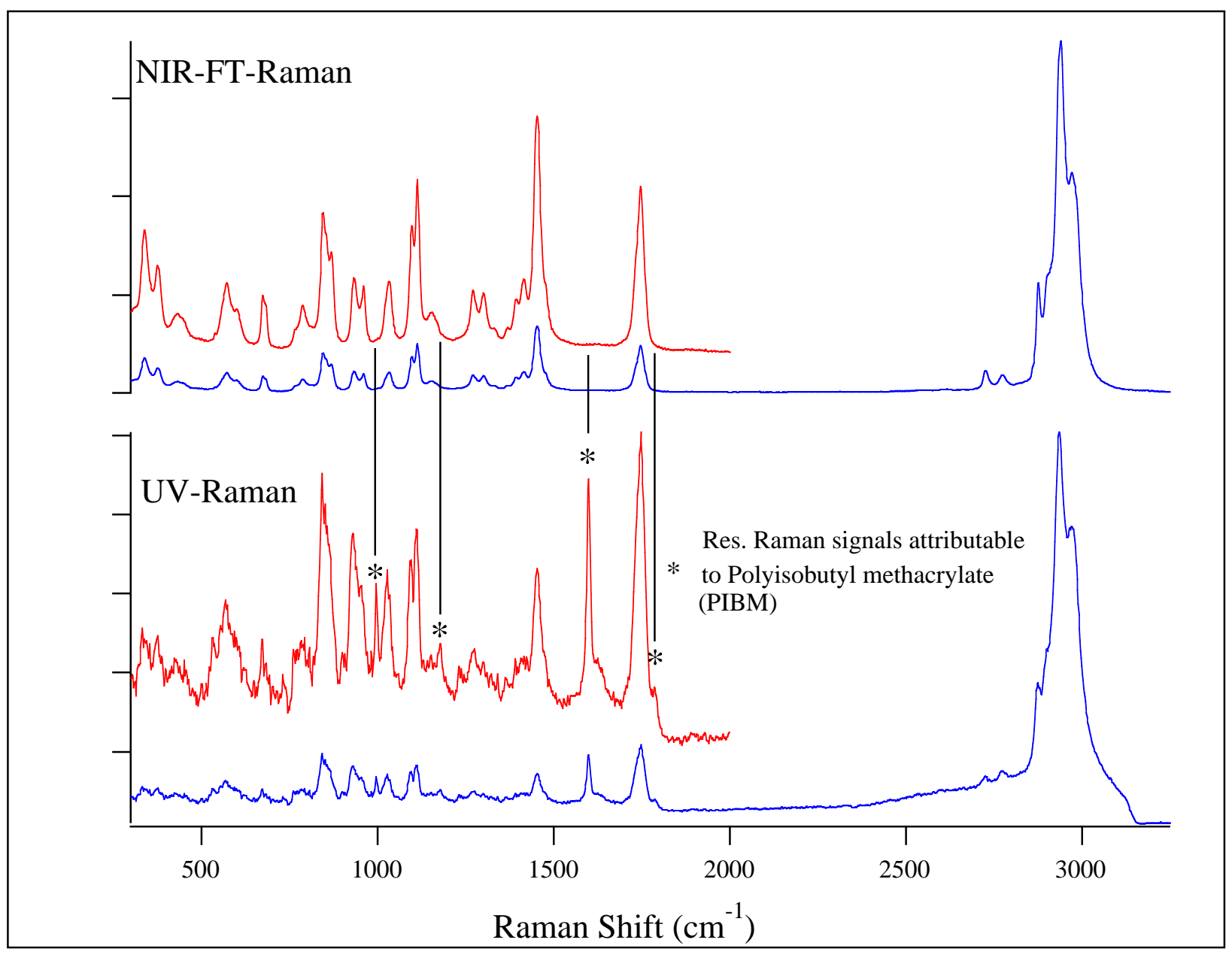

\begin{tabular}{|l|l|l|}
\hline \multicolumn{3}{|c|}{ Raman Shift $\left(\mathrm{cm}^{-1}\right)$} \\
\hline 331.407 & 995.339 & 1747.12 \\
\hline 375.283 & 1026.03 & 1778.19 \\
\hline 425.009 & 1091.06 & 2755.81 \\
\hline 567.431 & 1110.14 & 2872.67 \\
\hline 671.519 & 1176.73 & 2896.62 \\
\hline 780.809 & 1229.8 & 2933.89 \\
\hline 842.941 & 1271.38 & 2974.2 \\
\hline 860.374 & 1451.52 & 3062.89 \\
\hline 927.995 & 1598.2 & \\
\hline 951.115 & 1616.66 & \\
\hline
\end{tabular}

The weaker Raman signal (relative to neat DEM) observed for TDEM is attributed to the large backscatter signal that accompanied the desired Raman signal. The large backscattered signal has been tentatively ascribed to the polyisobutyl methacrylate. It is estimated that this $300,000 \mathrm{MW}$ "thickener" has a nominal diameter on the order to microns thereby resulting in Mie scattering contributions. It should also be noted that PIBM is also undergoing a significant resonance-enhanced as evidenced by new peaks at 995, 1176, 1598 , and $1778 \mathrm{~cm}^{-1}$. 


\section{Teflon}

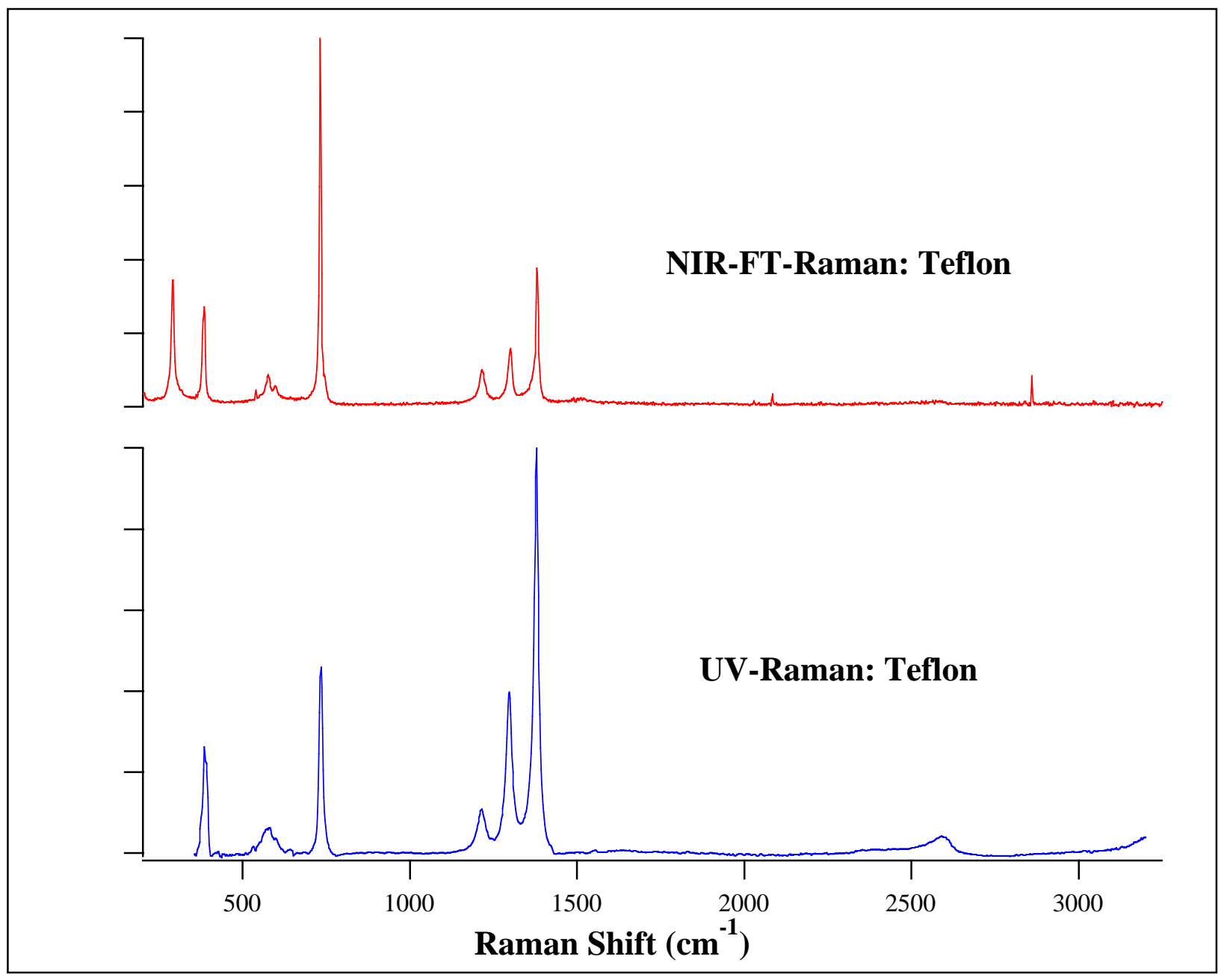

\begin{tabular}{|l|}
\hline \multicolumn{1}{|c|}{ Raman Shift $\left(\mathrm{cm}^{-1}\right)$} \\
\hline 386.717 \\
\hline 574.028 \\
\hline 733.515 \\
\hline 1213.53 \\
\hline 1296.33 \\
\hline 1377.56 \\
\hline 2567.3 \\
\hline
\end{tabular}




\section{Water}

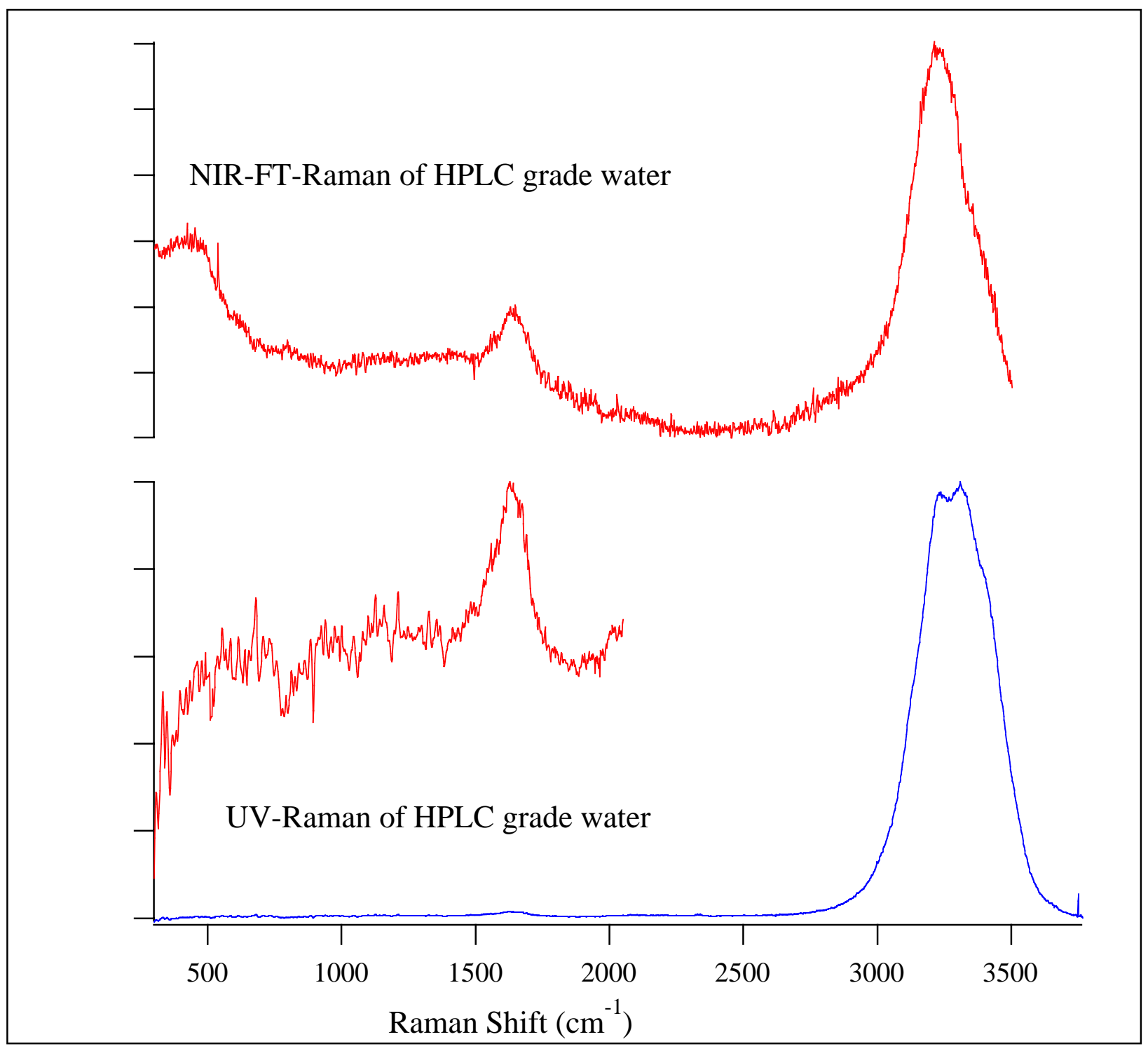

Raman Shift $\left(\mathrm{cm}^{-1}\right)$

1633.23

3292.12 
Photographs of MOPO-based UV Raman Laboratory

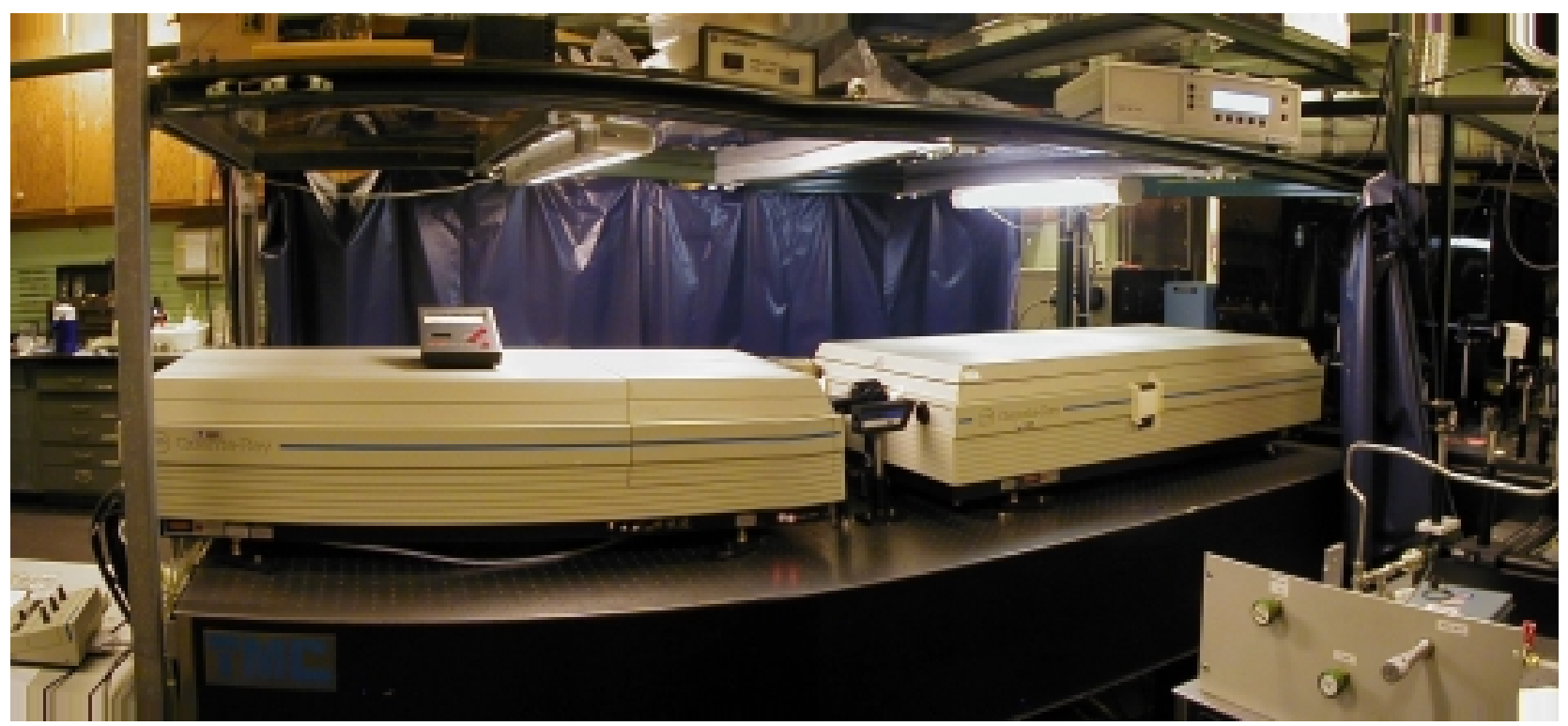

Figure 5: Spectra-Physics GCR 290 pumped MOPO 730 laser system

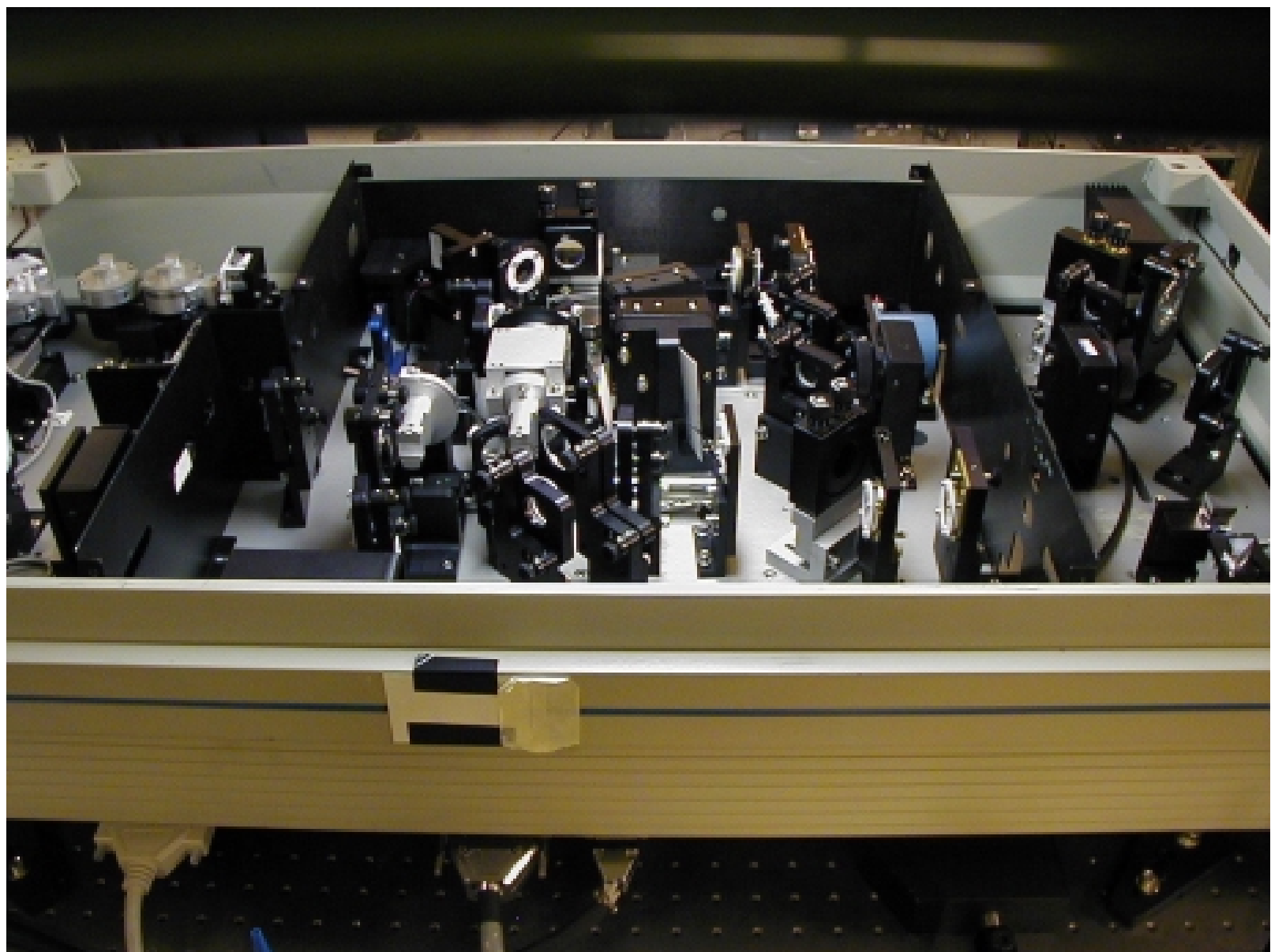

Figure 6: View inside the SP MOPO 730 head. Top is the Master Oscillator and bottom in the Power Oscillator 


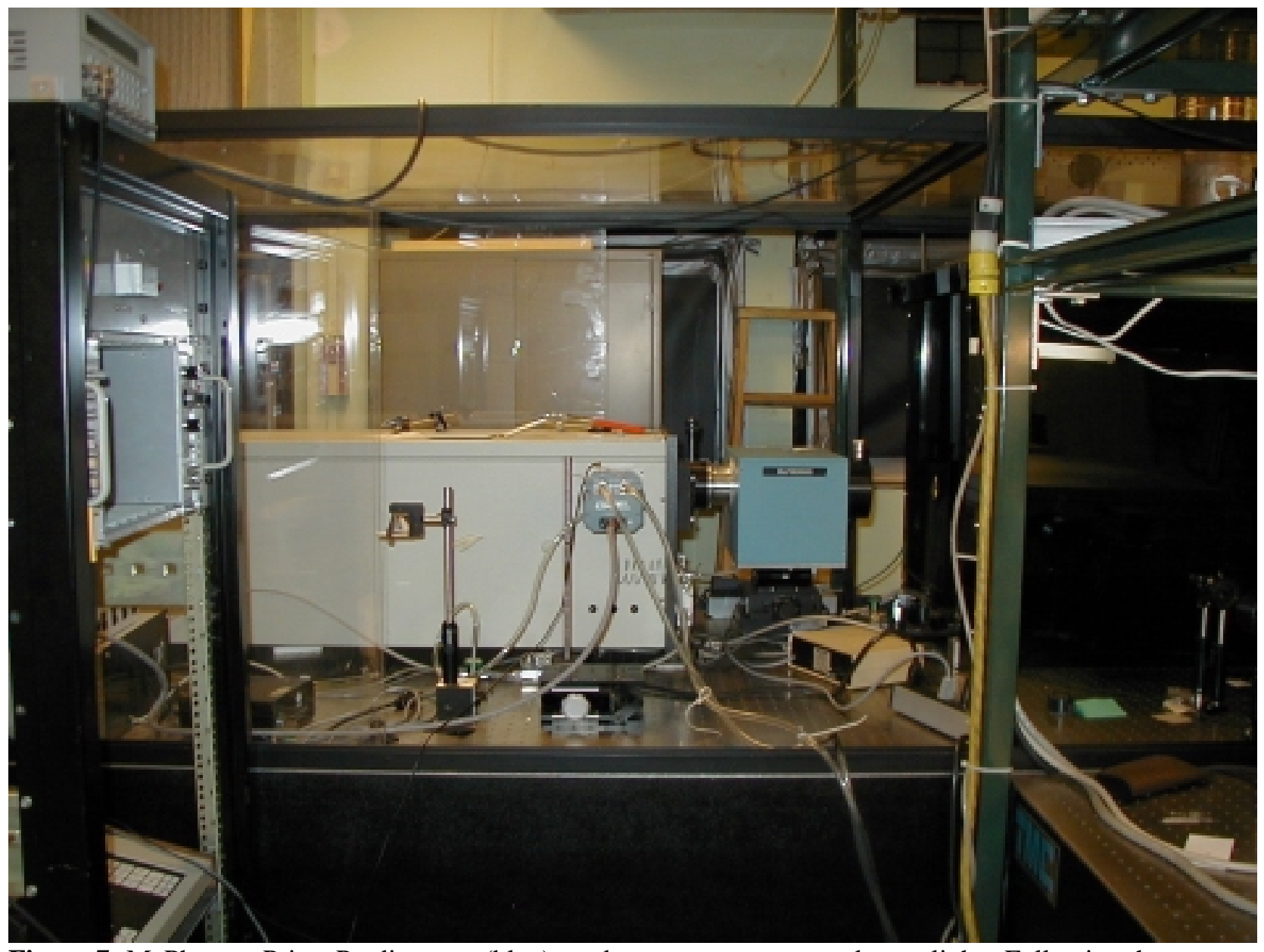

Figure 7: McPherson Prism Predisperser (blue) used to suppress unwanted stray light. Following the predisperser the scattered light enters a $1.26 \mathrm{~m}$ SPEX single-grating spectrometer and then exits to an array detector (Andor ICCD housed in an Oriel case). 


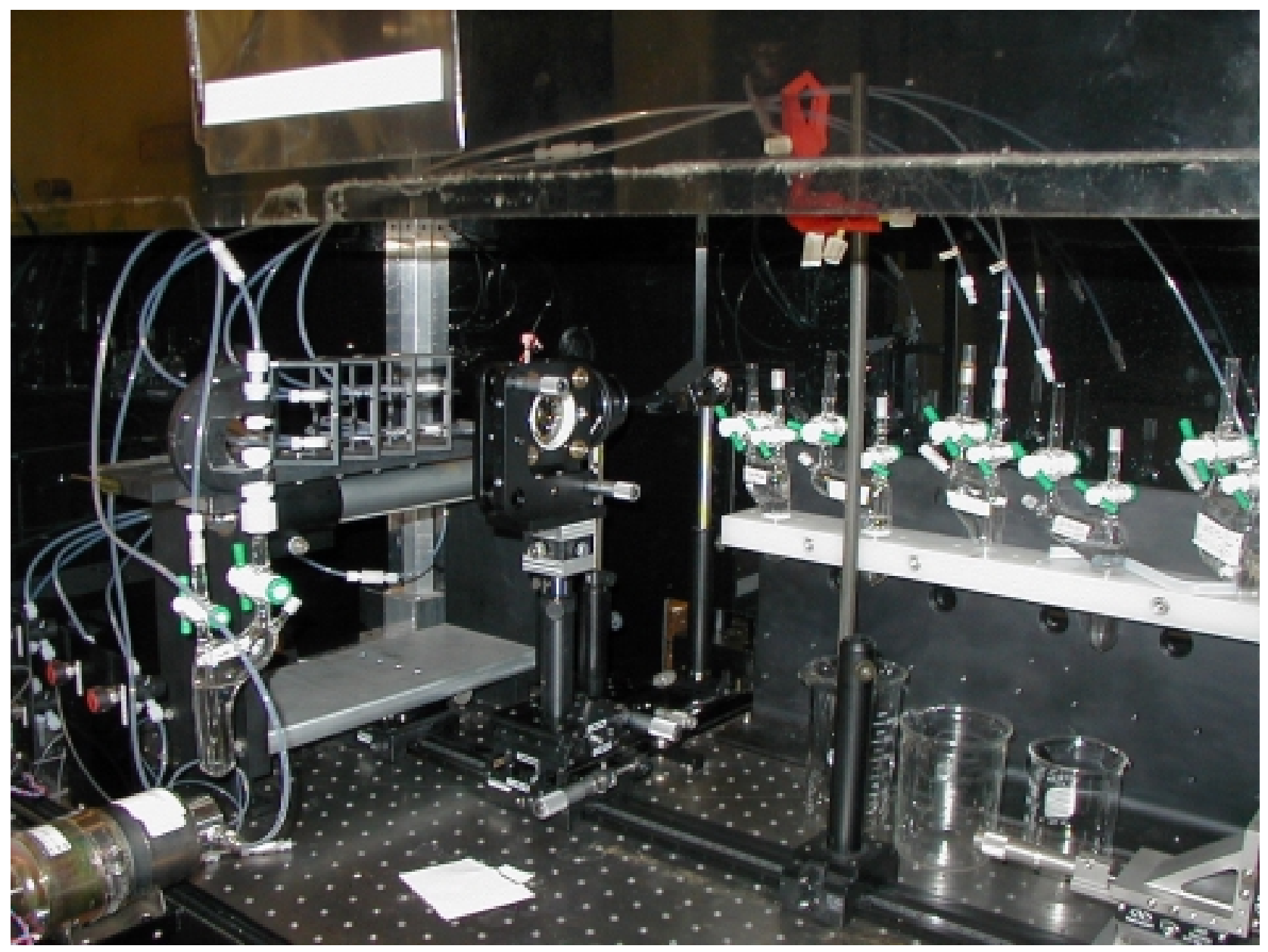

Figure 8: The sample compartment. Four standard quartz flow cells can be readily seen. Each cell is dedicated to a specific chemical thereby eliminating cross-contamination. To the left of the four quartz cells is the windowless flow cell. See Figures 9 and 10 for a more detailed picture of this flow cell. 


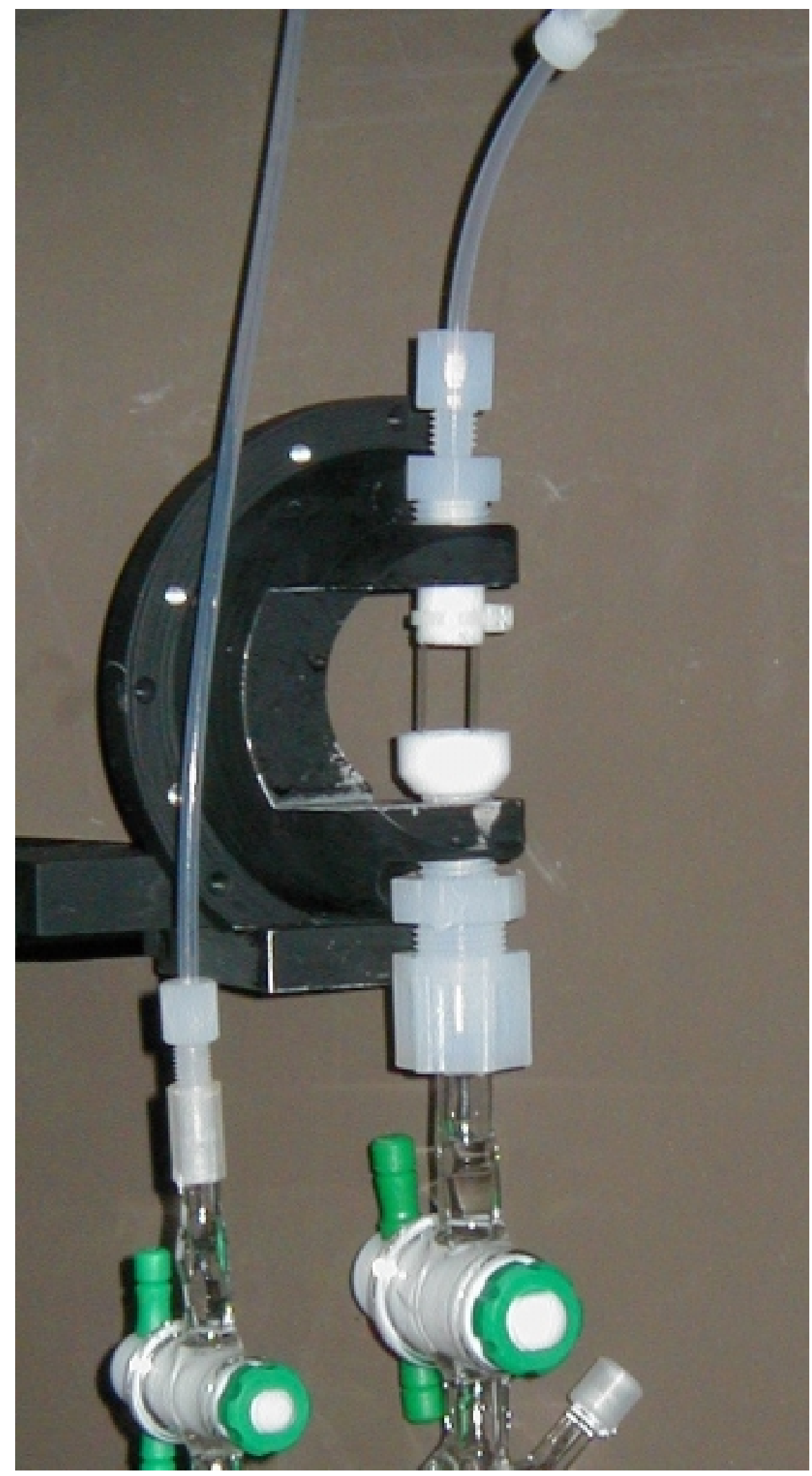

Figure 9: BNL designed windowless flow cell. This cell eliminates Raman signal contributions from the quartz flow cells. 


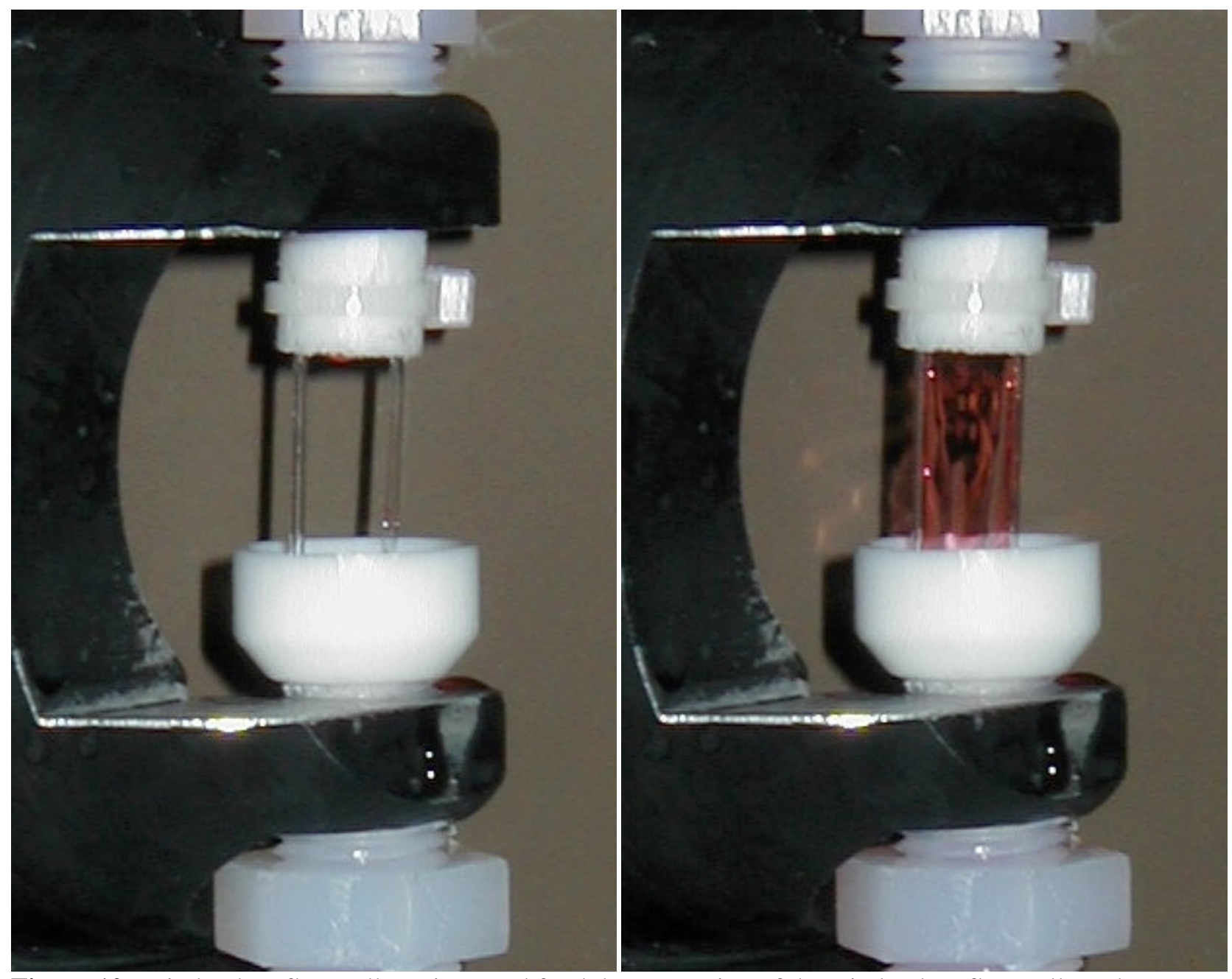

Figure 10: Windowless flow cell. Using a red food dye, operation of the windowless flow cell can be observed. For more viscous materials (TDEM, SF96), less turbulent structure is observed. 


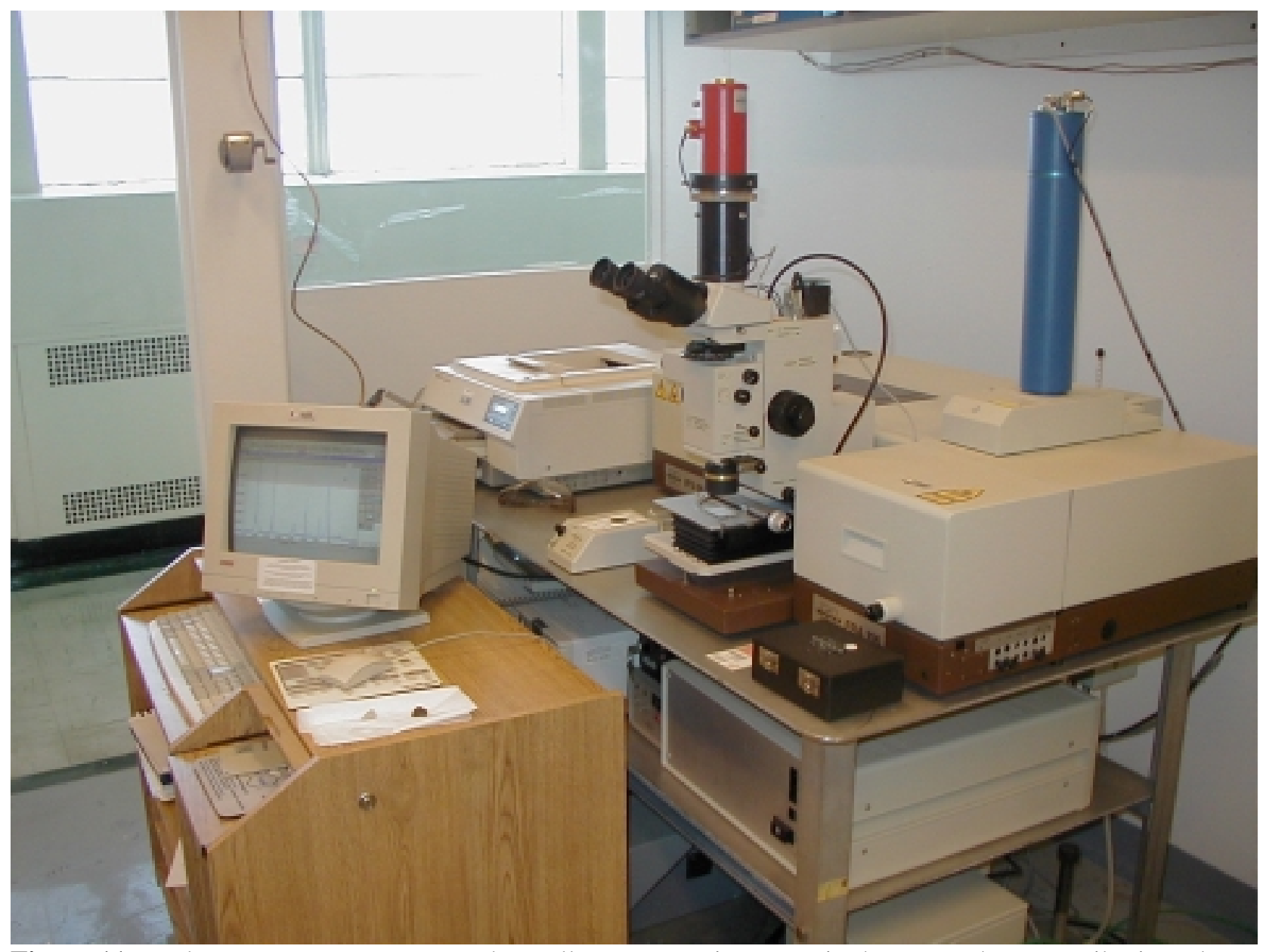

Figure 11: Bruker FT-Raman system used to collect Raman signatures in the NIR, where contributions due to resonance-enhancement are virtually non-existent. 


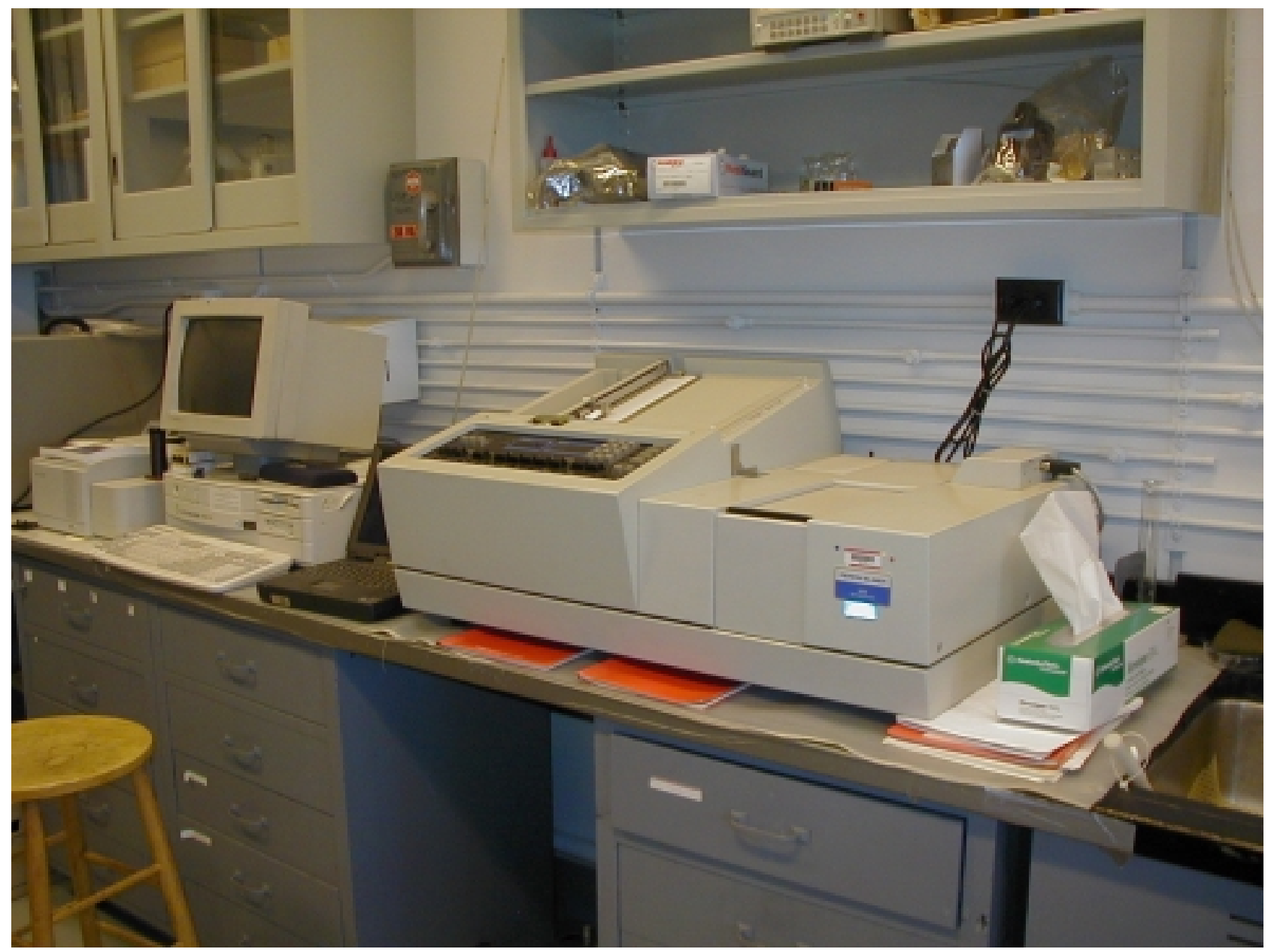

Figure 12: Perkin-Elmer 320 UV/VIS spectrophotometer (foreground) and an ATi Mattson Genesis Series FTIR (background). 


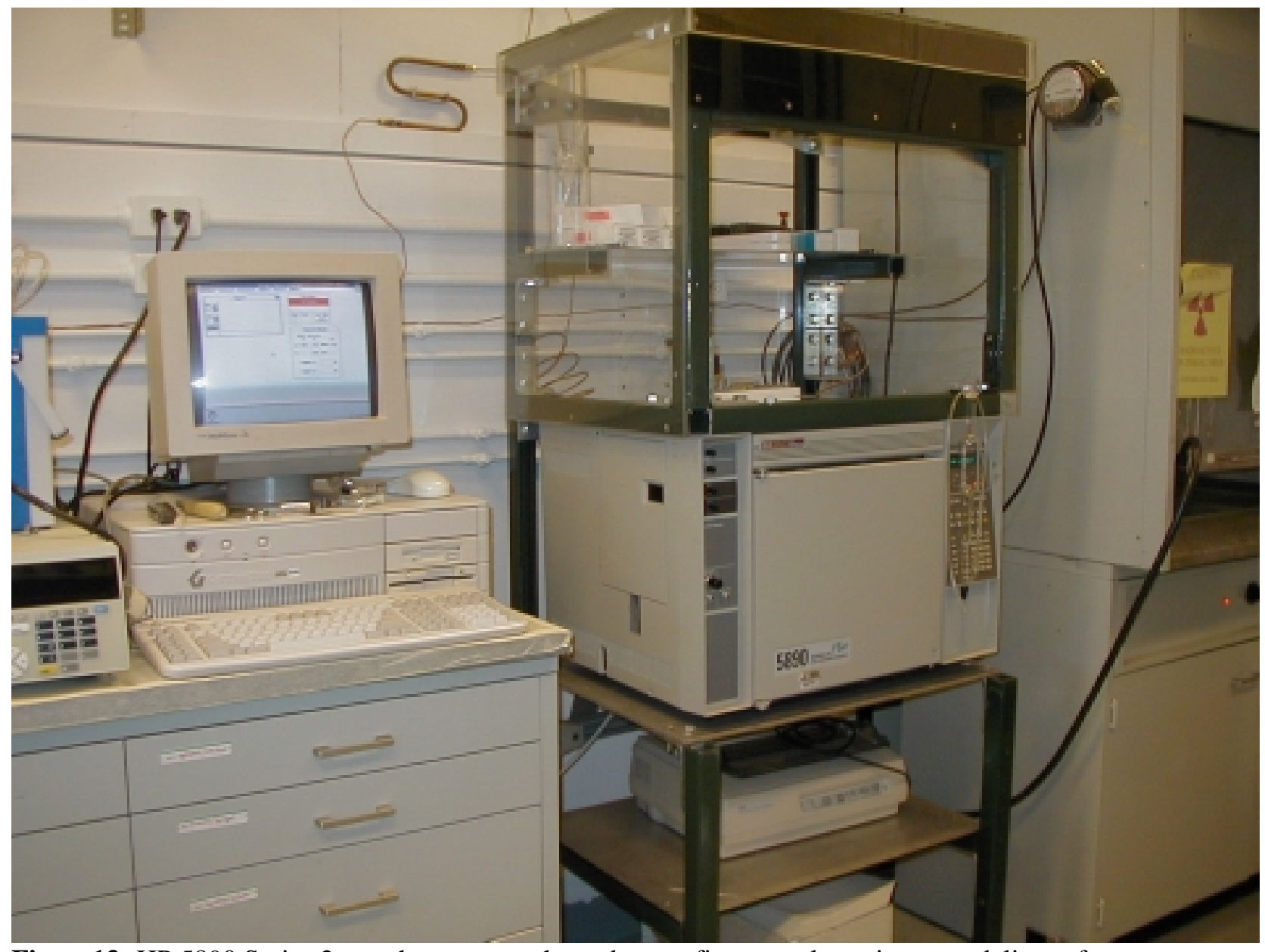

Figure13: HP 5890 Series 2 gas chromatograph used to confirm sample purity upon delivery from a supplier and to check for sample degradation during laser Raman experiments. 